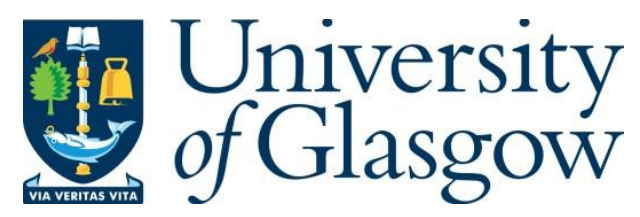

Li, W., Li, X., Ren, J. and Jiang, H. (2018) Length to diameter ratio effect on heat transfer performance of simple and compound angle holes in thin-wall airfoil cooling. International Journal of Heat and Mass Transfer, 127, pp. 867-879.

There may be differences between this version and the published version. You are advised to consult the publisher's version if you wish to cite from it.

http://eprints.gla.ac.uk/172424/

Deposited on: 8 November 2018

Enlighten - Research publications by members of the University of Glasgow http://eprints.gla.ac.uk 


\title{
Length to Diameter Ratio Effect on Heat Transfer Performance of Simple and Compound Angle Holes in Thin-
} Wall Airfoil Cooling

\author{
Weihong $\mathrm{Li}^{1}$, Xueying $\mathrm{Li}^{2}$, Jing Ren ${ }^{2}$, Hongde Jiang ${ }^{2}$ \\ 1: Systems, Power \& Energy Research Division, School of Engineering, University of Glasgow, Glasgow G12 8QQ, UK. \\ 2: Institute of Gas Turbine, Department of Energy and Power Engineering, Tsinghua University, Beijing, 100084, China.
}

\begin{abstract}
:
Heat transfer coefficients on a flat plate surface downstream a row of simple and compound angle cylindrical holes are investigated using high-resolution thermographic liquid crystal technique. A variation of flow parameters including blowing ratio, and geometry parameters including compound angle and length-to-diameter ratio are examined. Blowing ratios (M) ranging from 0.3 to 2 , length to diameter ratios (L/D) from 0.5 to 5 , and two compound angle $\left(\beta: 0^{\circ}, 45^{\circ}\right)$ are employed composing a test matrix of 70 test cases. Detailed local, spanwise averaged, and area averaged heat transfer coefficients $h_{f} / h_{0}$ are presented to illustrate the effect of length-to-diameter ratio and compound angle. The film cooling performance is also evaluated using NHFR method and $\Delta \varphi$ method by combining adiabatic film effectiveness and heat transfer coefficient data. Results indicate that $\Delta \varphi$ method has superiority in evaluating film cooling performance due to its direct reflection of temperature reduction by film protection.
\end{abstract}

\section{Introduction}

Modern heavy-duty gas turbines or aero-engines are requiring higher turbine inlet temperature to achieve more power generation and higher thermal efficiencies. Typical turbine inlet temperature has increased up to $2100 \mathrm{~K}$ for aero-engines which generates higher demand of turbine cooling. Common cooling techniques include internal cooling and film cooling. Coolant passes internal channels with different turbulent features and then injects through discrete holes to form a protective film on the turbine blade surface. Recently, some new blade concepts are proposed, for example, near wall cooling or double wall airfoil cooling [1] shown in Fig. 1, where small cooling cavities require impingement with low distance [2-4] and thinwall outer foil requires discrete film holes with short length-to-diameter ratio [5]. Due to manufacture limitations, shaped holes are difficult to use on the thin-wall airfoils, whereas simple angle and compound angle holes are suitable.

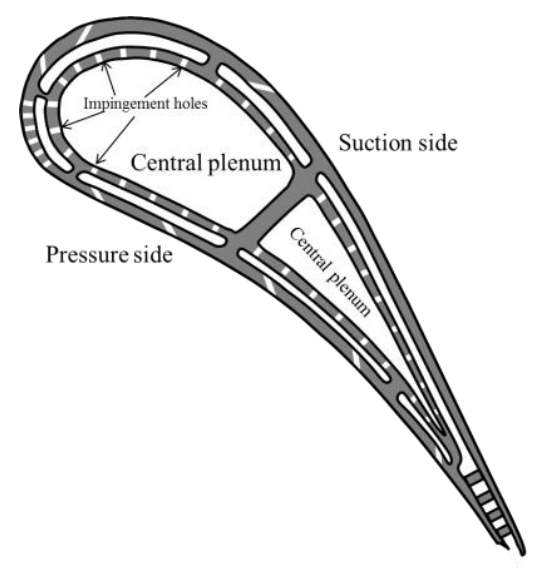

Fig. 1 Double wall cooling vane with short film holes.

A common method to evaluate the film cooling performance is the adiabatic film cooling effectiveness $\eta$, which is defined 
Table 1 Summary of simple and compound angle film cooling work

\begin{tabular}{|c|c|c|c|c|c|c|c|c|}
\hline Authors & Hole shape & $\mathrm{L} / \mathrm{D}$ & DR & $\mathrm{BR}$ & $\mathrm{P} / \mathrm{D}$ & $\alpha\left(^{\circ}\right)$ & $\beta\left(^{\circ}\right)$ & Data obtained \\
\hline Hay et al. [6] & Simple & - & 1 & $0.5-2.0$ & 3 & 35,90 & 0 & Heat transfer coefficient \\
\hline Ammari et al. [7] & Simple & - & $1-1.52$ & $0.5-2.0$ & 3 & 35,90 & 0 & Heat transfer coefficient \\
\hline Burd et al. [8-9] & Simple & $2.3 / 7.0$ & 0.96 & $0.5-1$ & 3 & 35 & 0 & $\begin{array}{l}\text { Adiabatic film effectiveness and flow field } \\
\text { measurements }\end{array}$ \\
\hline Baldauf et al. [10] & Simple & 6 & $1.2-1.8$ & $0.2-2.5$ & $2,3,5$ & $\begin{array}{l}30,60, \\
90\end{array}$ & 0 & $\begin{array}{l}\text { Adiabatic film effectiveness and heat transfer } \\
\text { coefficient }\end{array}$ \\
\hline Lutum et al. [11] & Simple & $1.75-18$ & 1.15 & $0.52-1.56$ & 2.86 & 35 & 0 & Adiabatic film effectiveness \\
\hline Sen et al. [12] & Simple & $1.16 / 2.91$ & 0.90 & $0.5-1.5$ & 3 & 35 & 45 & Heat transfer coefficient \\
\hline Ekkad et al. [13-14] & Compound & 4.6 & $\begin{array}{l}0.98- \\
1.46\end{array}$ & $0.5-2.0$ & 3 & 35 & 45 & $\begin{array}{l}\text { Adiabatic film effectiveness and heat transfer } \\
\text { coefficient }\end{array}$ \\
\hline Goldstein et al. [15] & Compound & 6.3 & 1.0 & $0.5-2.0$ & 3 & 35 & 45 & $\begin{array}{l}\text { Adiabatic film effectiveness and heat transfer } \\
\text { coefficient }\end{array}$ \\
\hline Nasir et al. [16] & Compound & 4.9 & 1.0 & $0.5-1.5$ & 3 & 55 & 60 & $\begin{array}{l}\text { Adiabatic film effectiveness and heat transfer } \\
\text { coefficient }\end{array}$ \\
\hline Ligrani et al. [17-18] & Compound & 8 & 1 & $0.5-1.5$ & $3-6$ & 35 & 60 & $\begin{array}{l}\text { Adiabatic film effectiveness and heat transfer } \\
\text { coefficient }\end{array}$ \\
\hline Boyd et al. [19] & Compound & $7.5-10$ & 1.0 & $0.3-1.5$ & 3 & 30 & 45 & Adiabatic film effectiveness \\
\hline Schreivogel et al. [20] & Shaped & $7.5-11.5$ & 1.7 & $0.5-2.5$ & $4-6$ & 30 & 0 & Adiabatic film effectiveness \\
\hline Present Study & $\begin{array}{l}\text { Simple } \\
\text { /Compound }\end{array}$ & $0.5-5$ & $1.0-1.5$ & $0.3-2.0$ & 5 & 35 & 45 & $\begin{array}{l}\text { Adiabatic film effectiveness and heat transfer } \\
\text { coefficient }\end{array}$ \\
\hline
\end{tabular}




$$
\eta=\frac{T_{\infty}-T_{a w}}{T_{\infty}-T_{c}}
$$

where $T_{\infty}$ is the mainstream temperature, $T_{c}$ is the coolant jet temperature exiting the film hole, and $T_{a w}$ is the adiabatic wall temperature. The adiabatic film effectiveness describes how well the coolant covers the metal surface and how the coolant mixes with the crossflow along the flow direction. In the real turbine cooling design, the adiabatic wall temperature is usually considered as the driving temperature in the third kind boundary condition. Additionally, information about the heat transfer coefficient is required to conduct the finite element analysis of metal airfoil and obtain the temperature/heat flux distributions. The superposition temperature is determined by assuming a steady state aerodynamic heating and constant fluid properties. So the energy equation can be simplified to a linear form and the heat flux can be determined by the following equation:

$$
q=h_{f}\left(T_{a w}-T_{w}\right)
$$

where $h_{f}$ is the heat transfer coefficient and $T_{w}$ is the metal wall temperature. In most cases, the heat transfer coefficient is expressed as heat transfer augmentation $h_{f} / h_{0}$, which means the ratio of the heat transfer coefficient with and without film cooling. The heat transfer coefficient augmentation $h_{f} / h_{0}$ indicates how the convective heat transfer process is influenced by adding film cooling jet.

Table 1 shows the comparison of the present study to previous experimental work on simple and compound angle holes [628]. Previous researches on the film cooling heat transfer coefficient measurement mainly concentrate on the effect of blowing ratio, density ratio, hole shape, and other flow parameters like mainstream turbulence intensity. Many of these studies were performed with simple angle hole. Hay et al. [6] used a swollen polymer surface and laser holographic interferometry technique to measure the heat transfer coefficient downstream a row of holes with injection angle of 35 deg and 90 deg. Ammari et al. [7] adopted similar experimental method as Hay et al. [6] to investigate the effect of density ratio on the heat transfer coefficient of film cooling. They found a heat transfer augmentation with increasing density ratio. Burd et al. $[8,9]$ provided hydrodynamic measurements for simple angle cylindrical hole with $\mathrm{L} / \mathrm{D}$ being 2.3 and 7.0. They reported that shortL/D holes have a "jetting" of coolant into freestream and enhance mixing. They also reported the association of the adiabatic film effectiveness with the fluid structures. Baldauf et al. [10] measured the heat transfer coefficient of a row of cylindrical ejection holes with IR-thermography technique. The parameters investigated included blowing angle, hole pitch, blowing rate, and density ratio. On the basis of large amount of experimental data, a new correlation was developed to correlate heat transfer coefficient with typical film cooling parameters. Lutum et al. [11] conducted experiments on simple angle cylindrical holes with L/D from 1.75 to 18 . Their results indicated that decreased film effectiveness was obtained for short hole and film effectiveness remained almost unchanged for $\mathrm{L} / \mathrm{D}>5$. But heat transfer coefficient data were not provided in their work.

Heat transfer coefficient augmentation using compound angle injection hole for film cooling has been measured by [1220]. Sen et al. [12] examined the effect of blowing ratio, hole spacing, and hole shape on the heat transfer coefficient with compound angle injection film hole. They showed that the heat transfer level was increased as compound angle increased. Thus they recommended that the combination of adiabatic effectiveness and heat transfer coefficient favors the performance evaluation of compound angle injection hole. Ekkad et al. $[13,14]$ used the transient liquid crystal method to measure the heat transfer coefficient downstream of simple angle and compound angle holes. Results with different density ratio and compound angle were compared. Their results indicated that increasing blowing ratio increased heat transfer coefficient. At a given blowing ratio, increasing density ratio also increased heat transfer coefficient. Goldstein et al. [15] used naphthalene sublimation technique to measure the heat transfer coefficient downstream a row of holes with 35 deg inclination angle and 45 deg compound angle. They found that the laterally averaged heat transfer coefficient of compound angle hole is close to that of simple angle hole at low blowing ratios, while the heat transfer coefficient drastically increases 10D downstream of 
injection hole at high blowing ratios due to the asymmetric vortex motion under the jets. Recently, Boyd et al. [19] and Schreivogel et al. [20] used new methods to measure two dimensional heat transfer coefficient distribution on shaped hole and trenched hole, respectively. Some recent works include hydrodynamic measurements [21] and combined investigation of film effectiveness and heat transfer coefficient [22]. Flow field data and heat transfer performance were correlated by illustrating the development of single asymmetric vortex. As mentioned above, double wall airfoil with thin-outer metal sheet requires simple angle hole or compound angle hole, so heat transfer performance of compound angle hole with short lengthto-diameter will be necessary. However, according to the authors' knowledge, no work exits investigating the effect of L/D on simple angle compound angle holes' heat transfer performance, especially the two dimensional heat transfer coefficient distributions.

This paper reports the experimental heat transfer coefficient measurements of simple angle and compound angle holes with varying blowing ratio and length-to-diameter ratio by steady liquid crystal (SLC). It is unique to present heat transfer coefficient data considering length-to-diameter ratio effect in simple angle and compound angle holes. Further, the paper proposes new correlations for the both simple angle and compound angle holes considering the length-to-diameter ratio, which is useful to design thin-walled film cooled airfoil. The adiabatic film effectiveness data of similar geometry configurations are presented in the Part I of the paper [23].

\section{Experimental Apparatus and Procedures}

\subsection{Low speed wind tunnel}

All the heat transfer coefficient experiments were performed in the low speed wind tunnel shown in Fig.2. Heat transfer coefficients measurements on the turbine vane endwall in this tunnel have been reported by Li et al. [22-24]. The test section has an inlet cross section of $0.24 \times 0.16 \mathrm{~m}^{2}$, and the mainstream velocity is set to $25 \mathrm{~m} / \mathrm{s}$ measured by a five-hole probe. Air is supplied to the test section from a variable speed blower, and the rectifier is used to obtain uniform mainstream.

An air compressor and high pressure gas tank are used to provide the coolant gas, i.e. air or $\mathrm{N}_{2} / \mathrm{CO}_{2}$, respectively. The coolant massflow rate is controlled and measured by electric mass flowmeters. The coolant temperature is adjusted by a heat exchanger prior to entering the mainstream and a difference within $0.5^{\circ} \mathrm{C}$ to mainstream temperature is ensured. The coolant temperature in the cavity is measured by thermocouples.

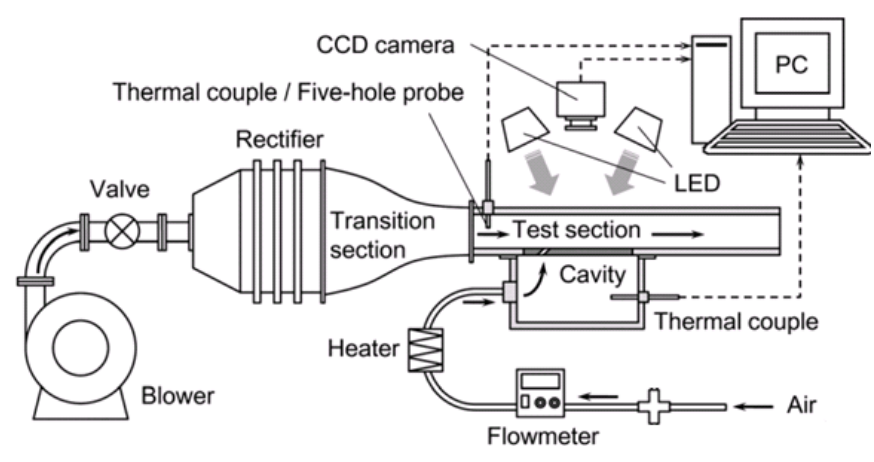

Fig. 2 Schematic view of the low speed wind tunnel

The approaching boundary layer and freestream turbulence intensity are measured by a constant temperature anemometer system (DANTEC90N10) with hot-wire probe from Dantec Inc. The probe is installed in the center of the wind tunnel and locates 10D in front of the film cooling holes. The measured voltages are converted to velocities using a polynomial fit from calibration. The approaching boundary layer distrbution is shown in Fig.3. The streamwise mean velocity is in good agreement 
with the near-wall log-law and the viscous sublayer trends $\left(\mathrm{u}^{+}=\mathrm{y}^{+}\right)$. The boundary layer characteristics are shown in Table 2. The boundary layer has a thickness of $\delta / D=1.89$, a displacement thickness of $\delta^{*} / \mathrm{D}=0.25$, a momentum thickness of $\kappa / D=0.2$, and a shape factor $\mathrm{H}=1.23$ typical for turbulent boundary layers. The inlet turbulence intensity is around 3.5\%.

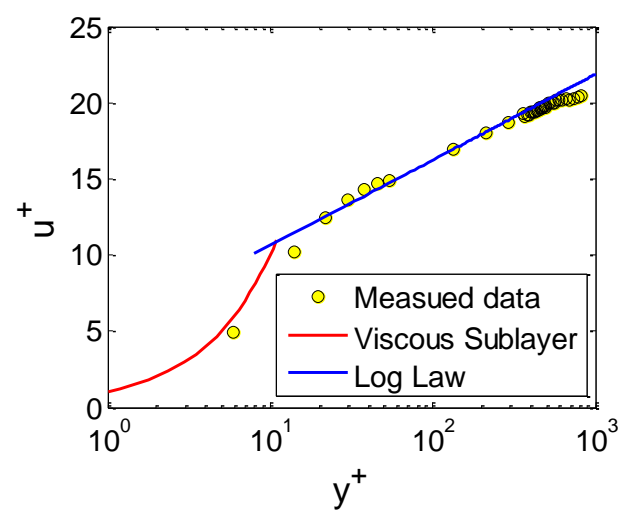

Fig. 3 Approach boundary layers measured at $x / D=-10$ for film cooling measurements

Table 2 Approaching boundary layer characteristics

\begin{tabular}{ccccc}
\hline \hline$\delta / \mathrm{D}$ & $\delta^{*} / \mathrm{D}$ & $\kappa / \mathrm{D}$ & $\mathrm{Re}_{\theta}$ & $\mathrm{H}$ \\
1.89 & 0.25 & 0.2 & 1032 & 1.23 \\
\hline \hline
\end{tabular}

\subsection{Film cooling configurations and test conditions}

Two different film cooling configurations are studied in the experiments, as shown in Fig. 4 . The injection angle $(\alpha)$ is $35^{\circ}$ for both the simple angle and compound angle holes. The compound angle $(\beta)$ is $45^{\circ}$ for the compound case. Both the film cooling configurations have the same pitch-to-diameter ratio (P/D) of 5. The length-to-diameter ratio (L/D) is varied from 0.5 to 5 as shown in Table 2. The film hole diameter $\mathrm{D}$ is $4 \mathrm{~mm}$ for all configurations. For each geometry, there are five holes in one row on the test plate to provide good periodicity. Spanwise and area averaged data are extracted from the middle three holes.

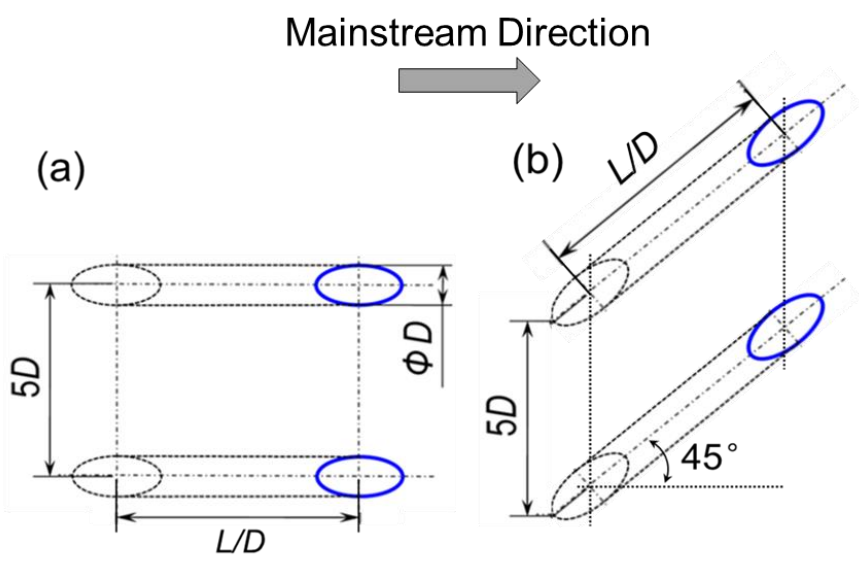

Fig. 4 Film hole configurations: (a) simple angle hole, (b) compound angle hole

The mainstream was set to $25 \mathrm{~m} / \mathrm{s}$ and the temperature was around $298 \mathrm{~K}$ in the experiments and coolant gas temperature was adjusted to fall within a $0.5{ }^{\circ} \mathrm{C}$ difference. Seven blowing ratios (M) were chosen to obtain film cooling effectiveness data from 0.3 to 2 as shown in Table 3 . Hence there are in total 70 sets of experiments performed for the simple hole and 
compound angle hole.

Table 3 Geometry configuration and test conditions

\begin{tabular}{ll}
\hline Parameter & Value \\
\hline$U_{m}$ & $25 \mathrm{~m} / \mathrm{s}$ \\
$T_{m}, T_{c}$ & $298 \mathrm{~K}$ \\
$\mathrm{DR}$ & $1.0\left(\mathrm{~N}_{2}\right)$ \\
$M$ & $0.3,0.5,0.8,1.0,1.2,1.5,2.0$ \\
$\mathrm{~L} / \mathrm{D}$ & $0.5,1,2,3.5,5$ \\
\hline \hline
\end{tabular}

\subsection{Heat Transfer Measurement Techniques}

The heat transfer coefficients are measured using steady liquid crystal and heat flux foil. Figure 5 shows the diagram of constant heat flux multilayer set-up, including steady liquid crystal layer, copper foil layer, heat foil layer, and insulation polystyrene layer. The replaceable film hole plate is also shown. The governing equation for the measurement technique is summarized as follows:

$$
\begin{gathered}
q-q_{\text {conduction }}-q_{\text {radiation }}=h_{f}\left(T_{w}-T_{c}\right) \\
q_{\text {conduction }}=\frac{k}{t}\left(T_{w i}-T_{i}\right), q_{\text {radiation }}=\sigma\left(T_{w}{ }^{4}-T_{\infty}{ }^{4}\right)
\end{gathered}
$$

where $T_{w}$ is the outer wall temperature, $T_{c}$ is the coolant temperature which is similar to the mainstream temperature, $T_{w i}$ is the heat foil inner side temperature measured by thermocouples, and $T_{i}$ is the plate surface temperature at the coolant plenum side measured by thermocouples. The conduction heat flux $q_{\text {conduction }}$ is calculated using Eq. (4) by measuring the $T_{w i}, T_{i}$, and the thickness/thermal conductivity of the Accura 25 plastic $(0.17 \mathrm{~W} /(\mathrm{m} \bullet \mathrm{K}))$. The radiation heat flux is calculated using Eq. (4) and then divided by the heat flux of heat foil. Hence, the radiation loss is estimated to be averagely $7 \%$ of the total heat flux. The Hallcrest-make steady liquid crystal sheet (R3520W) is pasted on the external side surface of the film plate. The copper foil is implemented to generate a more uniform heat flux distribution. The heat flux q of heat foil is calculated using the measured voltage and current. The polystyrene layer is used as insulation material to minimize heat conduction loss. The replaceable film hole plates are printed with additive manufacturing method using Accura 25 plastic. The steady liquid crystal, copper foil, and heat foil are extended around 8D upstream of film hole location. The purpose is to create a fully developed thermal boundary layer and avoid a sudden increase of heat transfer coefficient. In order not to disturb the film jet behavior, the copper foil and heat foil are drilled circle holes to overlap with the 3D-print film hole exit. The streamwise coordinate origin $\mathrm{x} / \mathrm{D}=0$ is set at the trailing edge of the hole. The $\mathrm{h}_{0}$ measurements were made with the holes covered with tape.

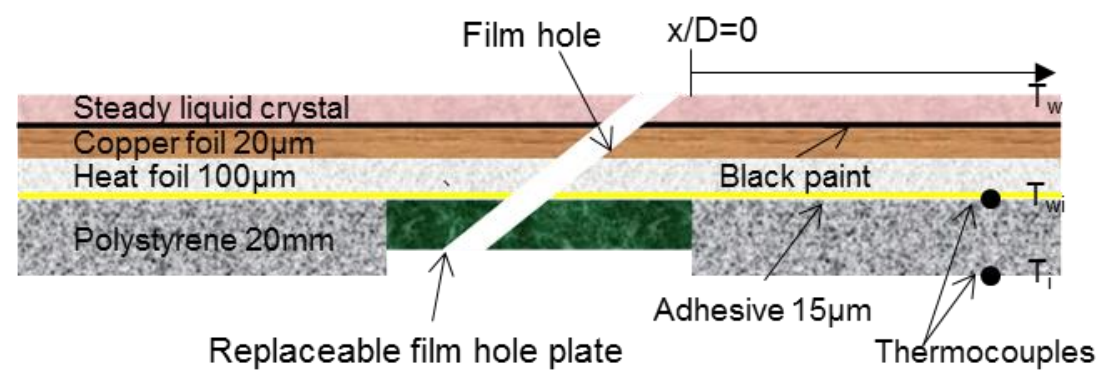

Fig. 5 Diagram of constant heat flux multilayer set-up

For steady liquid crystal, several factors can affect experimental accuracy, including the image noise reduction and the 
lighting angle. Previous researches indicated that the SLC coating thickness plays the most important role [27]. So the influence of coating thickness on the Hue-Temperature calibration line was investigated in the authors' previous work [28]. Figure 6 shows the calibration lines of four different coating thickness (thickness calculation method [29]). Comparatively large discrepancy is seen at the Hue range of 50-120, but the temperature variation is relatively insensitive to the Hue variation. Thus it is considered that the thickness exerts rare influence on the measurement accuracy. In the present work, the coating thickness is $45 \mu \mathrm{m}$. Meanwhile, a calibration curve of temperature versus hue is constructed by fitting fifth-order polynomial equation expressed as eq. (5), which is used to obtain the surface temperature at each point during the experiments.

$$
T=-1.35 \times 10^{-09} \text { Huе }^{5}-6.06 \times 10^{-7} \text { Hue }^{4}+1.03 \times 10^{-4} \text { Hиe }^{3}-7.86 \times 10^{-3} \text { Hue }^{2}+0.3213 \text { Hue }+33.79
$$

The sequential perturbation method proposed by Moffat [30] is utilized to calculate the uncertainty of $h_{f} / h_{0}$, which mainly depends on the imposed heat flux and the measured wall temperature with SLC. The heat flux $\mathrm{Q}_{0}$ is measured with an uncertainty of about $3.5 \%$. The conductive loss is less than $0.04 \mathrm{Q}_{0}$ and thus the uncertainty of $\mathrm{Q}_{0}$ is estimated to be $6.5 \%$. The wall temperature variation ranges from $\pm 0.8 \mathrm{~K}$ to $\pm 1.2 \mathrm{~K}$ with different coating thickness. The uncertainty of mainstream temperature and coolant temperature measurement is $0.2 \mathrm{~K}$. Typical values for heat flux and wall-coolant temperature head are $98 \mathrm{~W} / \mathrm{m}^{2}$ and $20 \mathrm{~K}$, thus the uncertainty on $\mathrm{h}_{\mathrm{f}} \mathrm{h}_{0}$ is $8.5 \%$.

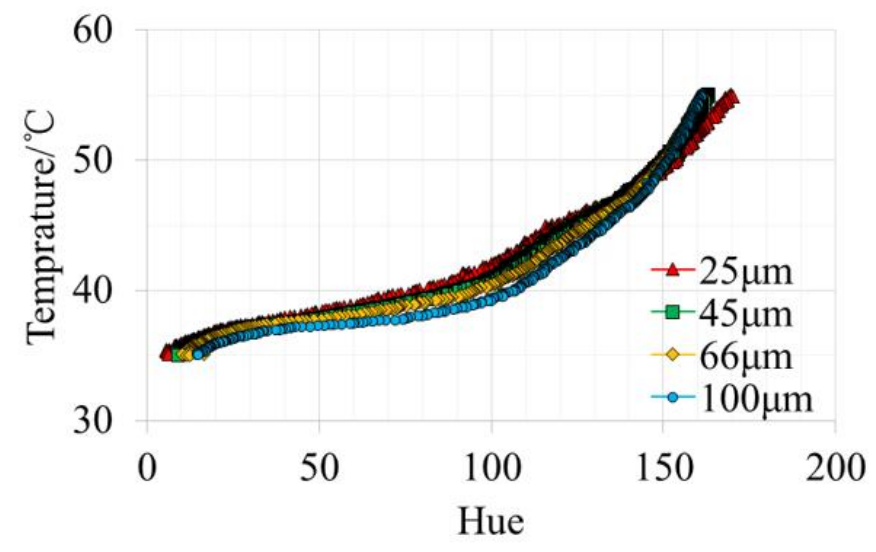

Fig. 6 Diagram of constant heat flux multilayer set-up

\section{Results and Discussions}

\subsection{Comparison with other investigations}

Figure 7 shows the spanwise averaged heat transfer coefficient augmentation $h_{f} / h_{0}$ comparison between present data and published data from Hay et al. [6], Ammari et al. [7], Goldstein et al. [15], Baldauf et al. [10], and Yuen et al. [31] for simple angle hole, as well as Ekkad et al. [15] and Goldstein et al. [16] for compound angle hole. The present pitch-to-diameter ratio of 5, length-to-diameter ratio of, and density ratio of 1.0 are quite similar to the published data. Generally, the agreement is quite good for simple angle hole and compound angle hole in varied blowing ratios, which indicates the effectiveness of the present heat foil-steady liquid crystal measurement technique. 

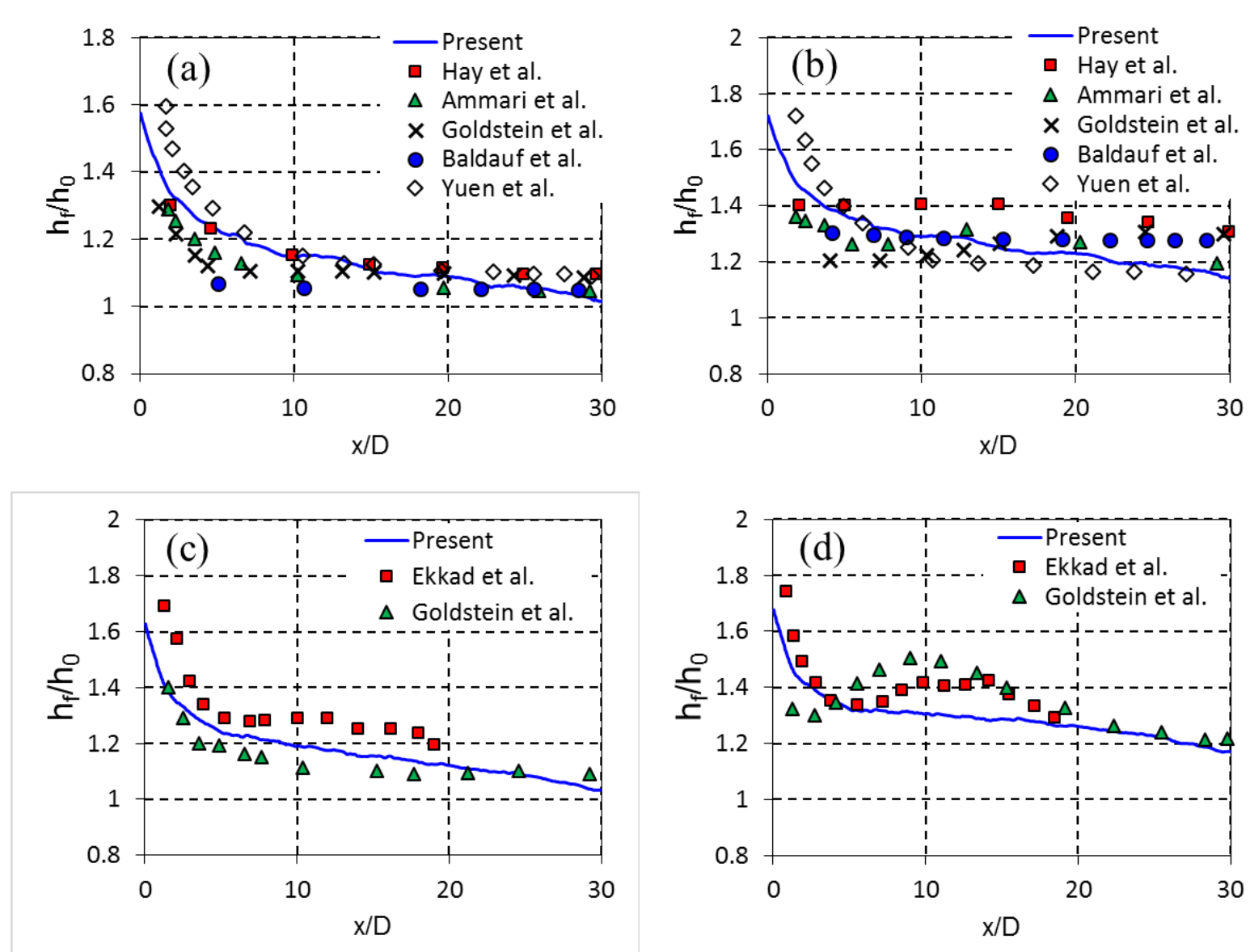

Fig. 7 Spanwise averaged heat transfer coefficient $h_{f} / h_{0}$ comparison with published data: (a) simple angle hole $M=1$, (b) simple angle hole $M=2$, (c) compound angle hole $M=1$, (d) compound angle hole $M=2$.

\subsection{Heat transfer coefficient}

The results follow the objectives with discussion on the effect of blowing ratio, compound angle, and length-to-diameter ratio. Detailed heat transfer coefficient distribution, spanwise averaged data, and area averaged data are shown. Also included is the comparison of two methods which are used to evaluate the overall cooling effectiveness, i.e. net heat flux reduction (NHFR) method [32] and Delta-Phi $(\Delta \varphi)$ method [33].

\subsubsection{Effect of blowing ratios}

Figure 8 shows the heat transfer coefficient $h_{f} / h_{0}$ distribution of simple angle and compound angle hole for varied blowing ratio with $\mathrm{L} / \mathrm{D}=3.5$. It is shown that the heat transfer coefficient $h_{f} / h_{0}$ increases with the increase of the blowing ratio, regardless of compound angle. The heat transfer coefficient reaches the highest value when $\mathrm{M}=2.0$. This is in contrast to the film effectiveness data where the high blowing ratio results in low film effectiveness due to jet lift-off. Evidently the fluid mechanism of coolant influencing the film effectiveness and heat transfer coefficient is different. The high film effectiveness is due to the proximity of coolant to the wall. However, high heat transfer coefficient is caused by the intense jet-crossflow interaction which enhances the turbulence intensity of near-wall flow and reduces the boundary layer thickness.

Figure 8a shows high heat transfer coefficient downstream the film hole as the blowing ratio increases. The high $\mathrm{h}_{\mathrm{f}} / \mathrm{h}_{0}$ regions downstream the hole is due to the coolant injection which causes high turbulence and high shearing motions. From $\mathrm{x} / \mathrm{D}=0$ to $\mathrm{x} / \mathrm{D}=6$, the coolant trace is apparent in the contour maps: high $\mathrm{h}_{\mathrm{f}} / \mathrm{h}_{0}$ appears in the middle region, while low $h_{f} / h_{0}$ 
appears in the two side regions. The counter rotating vortex pair (CRVP) entrains hot gas to mix with coolant and thins the boundary layer. The high shearing motions also generate high turbulence, which contribute to enhance heat transfer coefficient. As the fluid convects downstream, the jet trajectory is gradually diffused by the mixing process of coolant jet and surrounding hot gas. The boundary layer entrainment effect becomes less significant and the coolant trace grows fuzzy. There several parallel strips appear. The place where the coolant trace grows unconspicuous is influenced by the mainstream turbulence intensity. Higher mainstream turbulence intensity leads to higher coolant dissipation, and then the parallel strips appear at lower $\mathrm{x} / \mathrm{D}$. In the present work, the mainstream turbulence intensity is around 5\%, which is relatively high and so there exit the parallel strips for all the simple angle holes.

Figure $8 \mathrm{~b}$ shows the heat transfer coefficient distribution of compound angle hole. In the compound angle hole, the predominate flow structure is the single asymmetric main vortex (SAMV), which entrains the hot gas to the wall at one side and piles up the boundary layer at the other side [21]. The entrainment effect leads to high shearing motions and generates high turbulence mixing, which contributes to enhance the heat transfer coefficient. The boundary layer pile-up contributes to thinner boundary layer and thus enhances the heat transfer coefficient. The concerted action of entrainment and boundary layer pile-up generates a region of high heat transfer coefficient, which resembles finger-like patterns. Two regions are noticed in the heat transfer coefficient contour maps: high heat transfer coefficient at small $\mathrm{x} / \mathrm{D}$ and finger-like patterns at large $\mathrm{x} / \mathrm{D}$. Theses finger-like patterns actually show the coolant traces, where high turbulence intensity fluid concentrates and thinner boundary layer happens. The finger-like patterns are deflected more severely as the blowing ratio increases. Generally, the jet-crossflow shear effect of the compound angle hole is more significant than that of the simple angle hole [22], so the heat transfer coefficient downstream the hole is much than that of the simple angle hole.

(a)
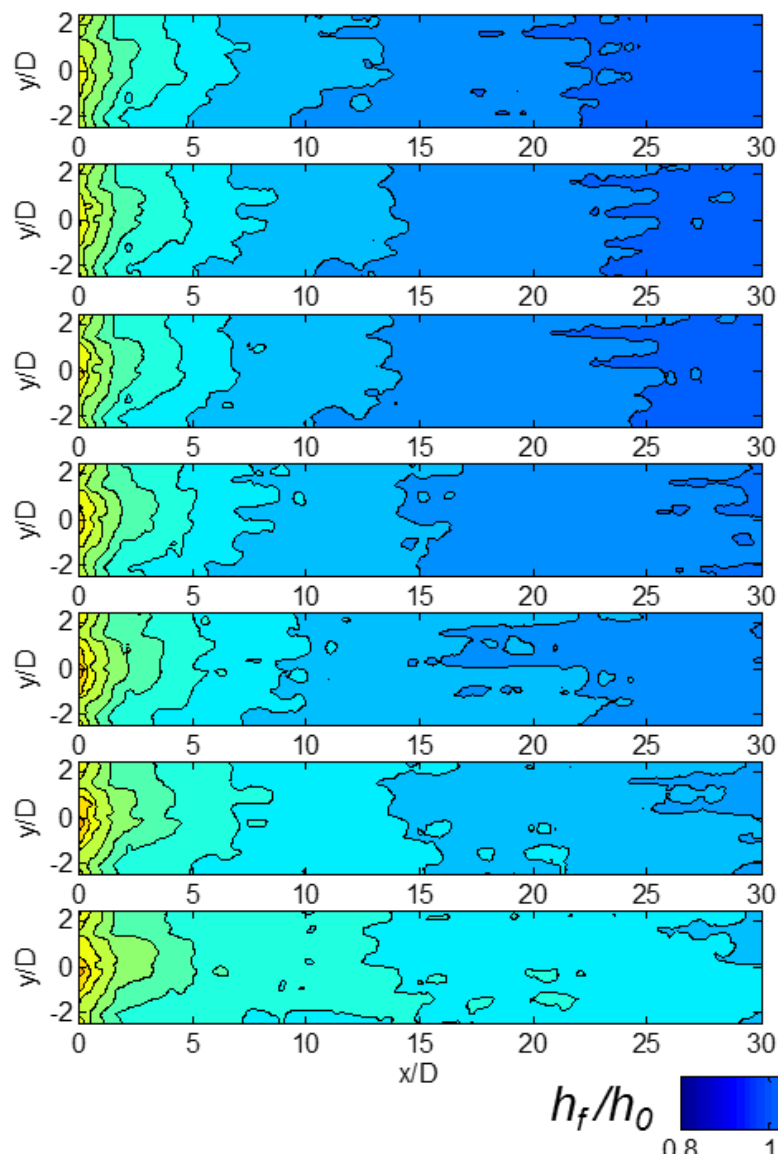

(b)

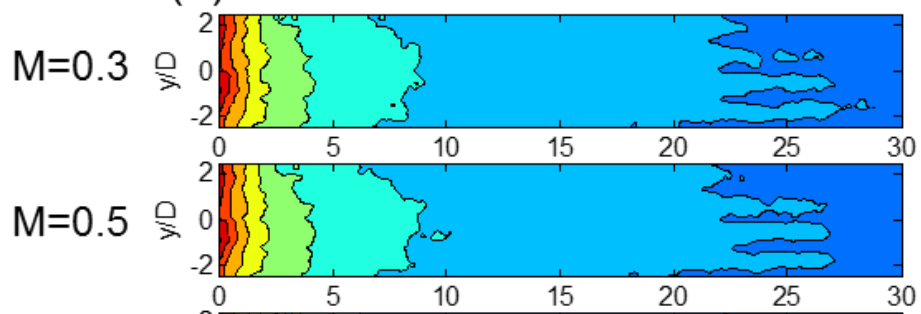

$M=0.8$

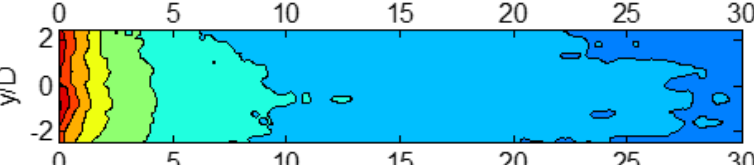

$M=1.0$

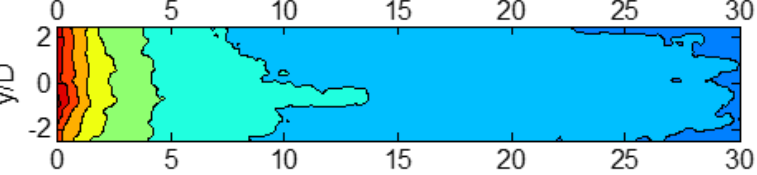

$M=1.2$
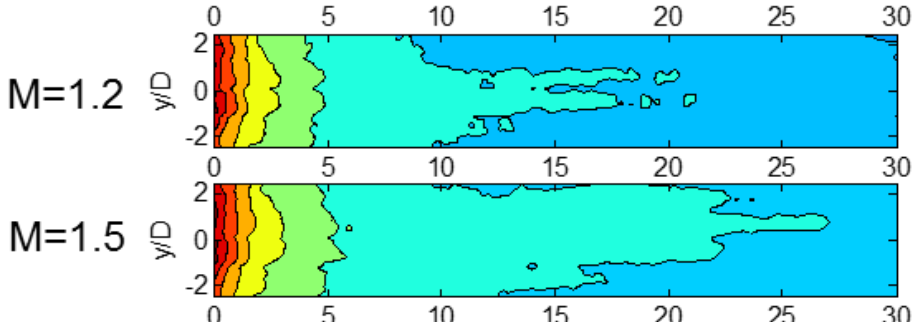

$M=2.0$

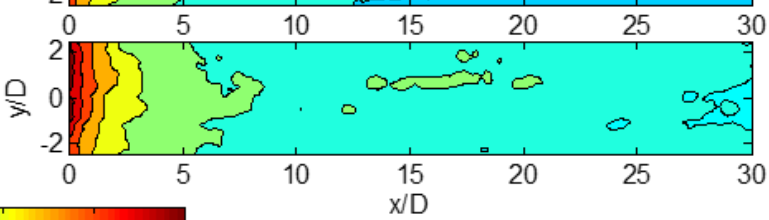


Fig. 8 Heat transfer coefficient $h_{f} / h_{0}$ distribution for varied blowing ratio with $L / D=3.5$, (a) simple angle hole and (b) compound angle hole

Figure 9 shows the spanwise averaged heat transfer coefficient of simple angle and compound angle hole with $\mathrm{L} / \mathrm{D}=3.5$. The spanwise averaged heat transfer coefficient of the simple angle and compound angle hole increases with the increase of blowing ratios. Higher blowing ratio results in higher jet momentum and causes higher rate of mixing, and then intensifies the dominant vortex structures (CRVP in simple angle hole and SAMV in compound angle injection hole) as well as other less prominent wake vortices. It is worth noting that the $h_{f} / h_{0}$ of compound angle hole reaches 1.8 downstream the hole, while it reaches 1.4 for the simple angle hole. As the compound angle reduces the jet vertical momentum and leads to better proximity of coolant to wall, the initial mixing rate is higher for compound angle injection hole, and the vigorous mixing manifested by the dominant vortex structures and wake vortices for the 45 deg case leads to the enhanced heat transfer downstream the hole. Also note that the heat transfer coefficient is less than or equal to 1.2 when $\mathrm{x} / \mathrm{D}$ is greater than 5 , indicating that the heat transfer coefficient augmentation due to film cooling is less obvious as the jet moves downstream.
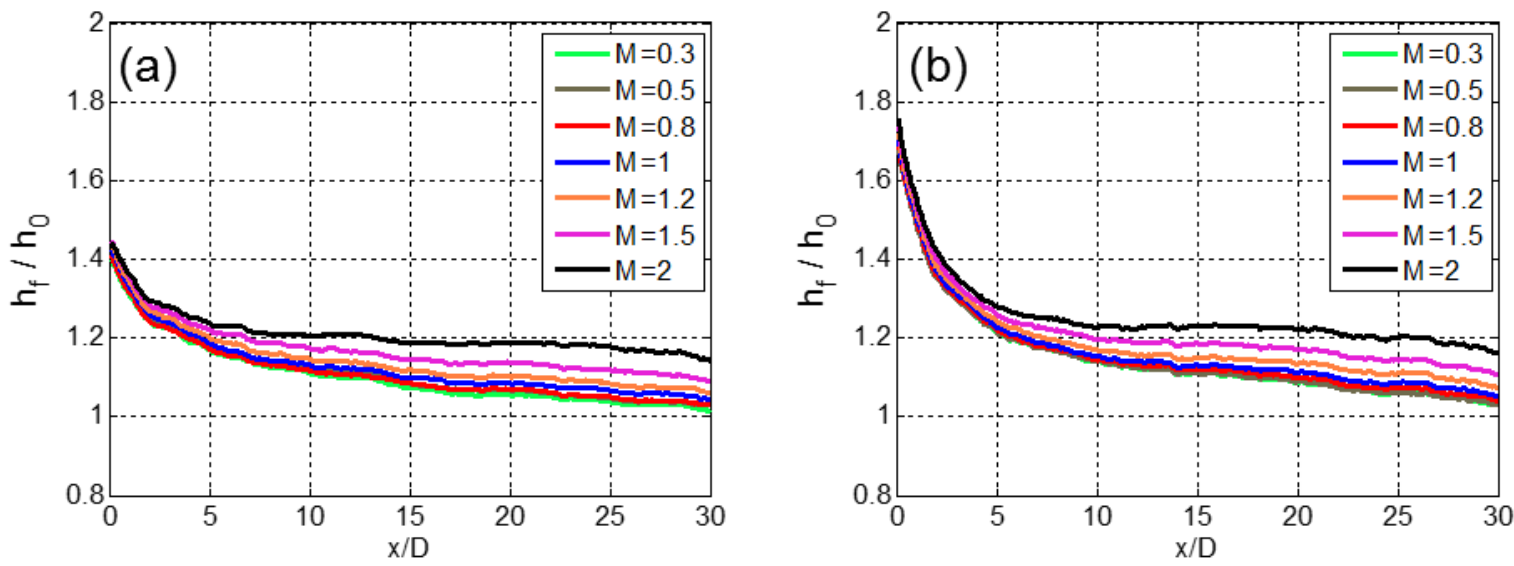

Fig. 9 Spanwise averaged heat transfer coefficient $h_{f} / h_{0}$ for varied blowing ratio with $L / D=3.5$, (a) simple angle hole and (b) compound angle hole

\subsubsection{Effect of compound angle}

The effect of compound angle on heat transfer coefficient is also investigated with different length-to-hole diameter ratio. Figure 10 shows heat transfer coefficient $h_{f} / h_{0}$ distribution for simple angle hole and compound angle hole with $L / D=0.5$ and 5.0. In Fig. 10a, the compound angle effect on the jet flow is slight because the $\mathrm{L} / \mathrm{D}$ value is small. The heat transfer coefficient patterns are basically the same for the simple angle and compound angle holes. For the $\mathrm{L} / \mathrm{D}=0.5$, the CRVP and the SAMV are not fully developed and tend to dissipate fast as the jet moves downstream. This is due to the high jet core turbulence intensity that enhanced the dissipation and diffusion of the dominant vortex structures. At downstream locations, the appearance of parallel strips indicates less obvious coolant trace and stronger vortex structures dissipation. Note that the heat transfer coefficient of compound angle hole is slightly higher behind $\mathrm{x} / \mathrm{D}=10$, even though the SAMV is not fully developed.

In Fig. 10b, for $L / D=5$, the overall heat transfer coefficient magnitude is lower than $L / D=0.5$. The main reason is that the jet core turbulence intensity is much higher in $L / D=0.5$. As the blowing ratio increases, the effect of compound angle grows more significant, by observing the "finger-like" patterns in the compound angle case. As stated above, the finger-like patterns are the results of concerted action of hot-gas entrainment and boundary layer pile-up. The single asymmetric main vortex is strengthened as the jet momentum increases, as well as the hot-gas entrainment and boundary pile-up motions. The hot-gas entrainment on the leeward of SAMV enhances turbulence mixing rate and contributes to higher heat transfer coefficient. The boundary layer pile-up on the windward of SAMV rolls the near-wall fluid and makes the boundary layer thinner, resulting 
in higher heat transfer coefficient. Therefore, the finger-like patterns where high heat transfer coefficient happens coincide with the trajectory of SAMV and reflect the coolant trace.

(a)
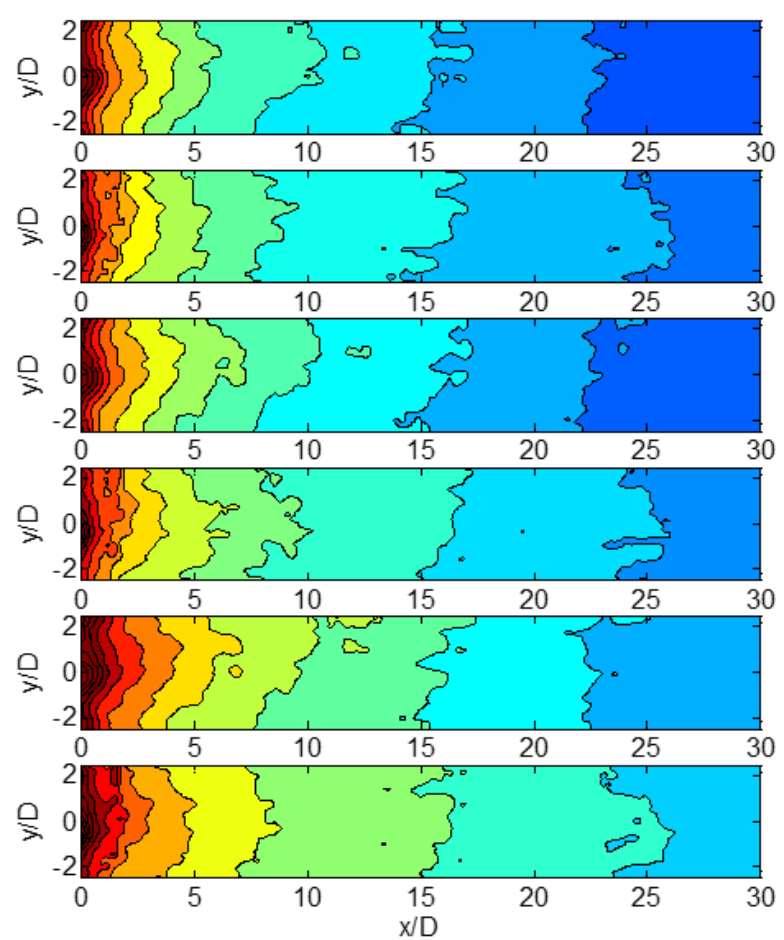

(b)

Simple $M=0.3$

Compound $M=0.3$

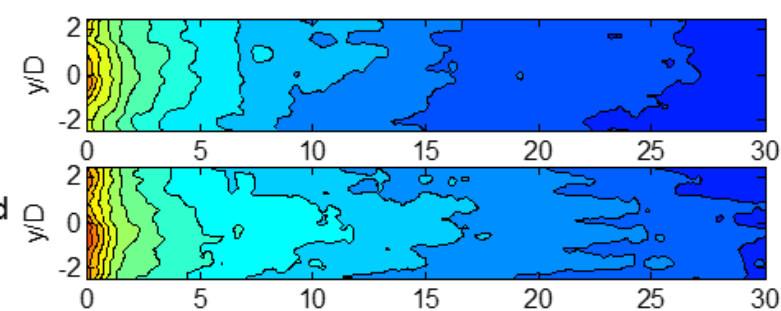

Simple $M=0.8$

Compound $M=0.8$
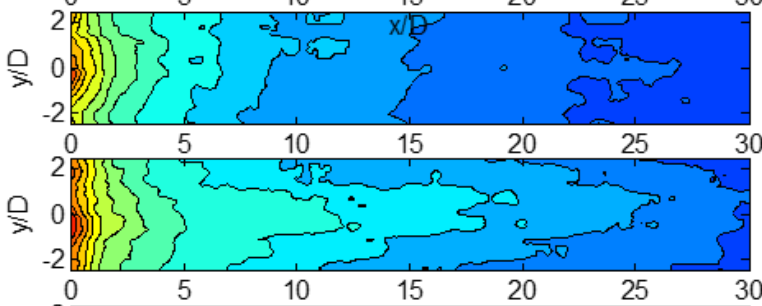

Simple $M=1.5$ Compound
$M=1.5$
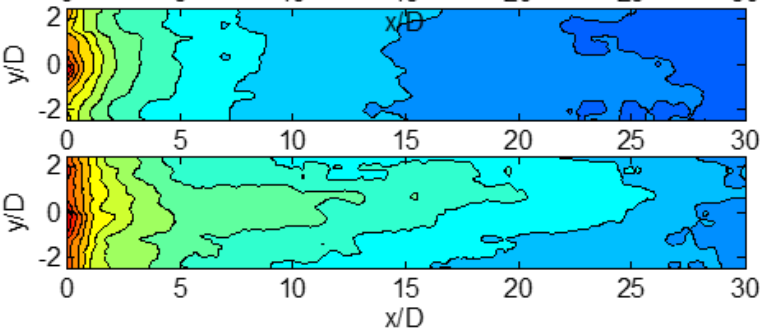

$h_{f} / h_{0}$

30
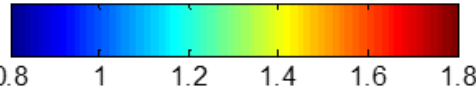

Fig. 10 Heat transfer coefficient $h_{f} / h_{0}$ distribution for simple angle hole and compound angle hole with (a) $L / D=0.5$ and $(b) L / D=5.0$ with varied blowing ratio.

Figure 11 shows the spanwise averaged heat transfer coefficient $h_{f} / h_{0}$ distribution for simple angle hole and compound angle hole with $\mathrm{L} / \mathrm{D}=0.5$ and 5.0. Figure 11a shows that in the case of $\mathrm{L} / \mathrm{D}=0.5$, the compound angle can also improve the heat transfer coefficient compared with simple angle hole. It is worth noting that the heat transfer coefficient of the simple angle hole at $\mathrm{M}=1.5$ is higher than that of the compound angle hole at $\mathrm{M}=0.3$ and 0.8 , which is ascribed to the strong jetcrossflow mixing at high blowing ratio. Figure 11b shows that the compound angle improves the heat transfer coefficient to a larger extent when length-to-diameter ratio is larger. It can be observed that the heat transfer coefficient of compound angle hole at $\mathrm{M}=0.3$ is comparable to that of simple angle hole at $\mathrm{M}=1.5$. The compounding of jet divides the jet momentum into vertical and lateral components, and so the reduced vertical component of momentum leads to a better proximity of coolant to wall. A greater near-wall bulk mass provides enhanced heat transfer coefficients. Meanwhile, the coherent unsteadiness in the wake zone under the SAMV is large and well spread out [21], which also leads to enhanced heat transfer coefficients. 

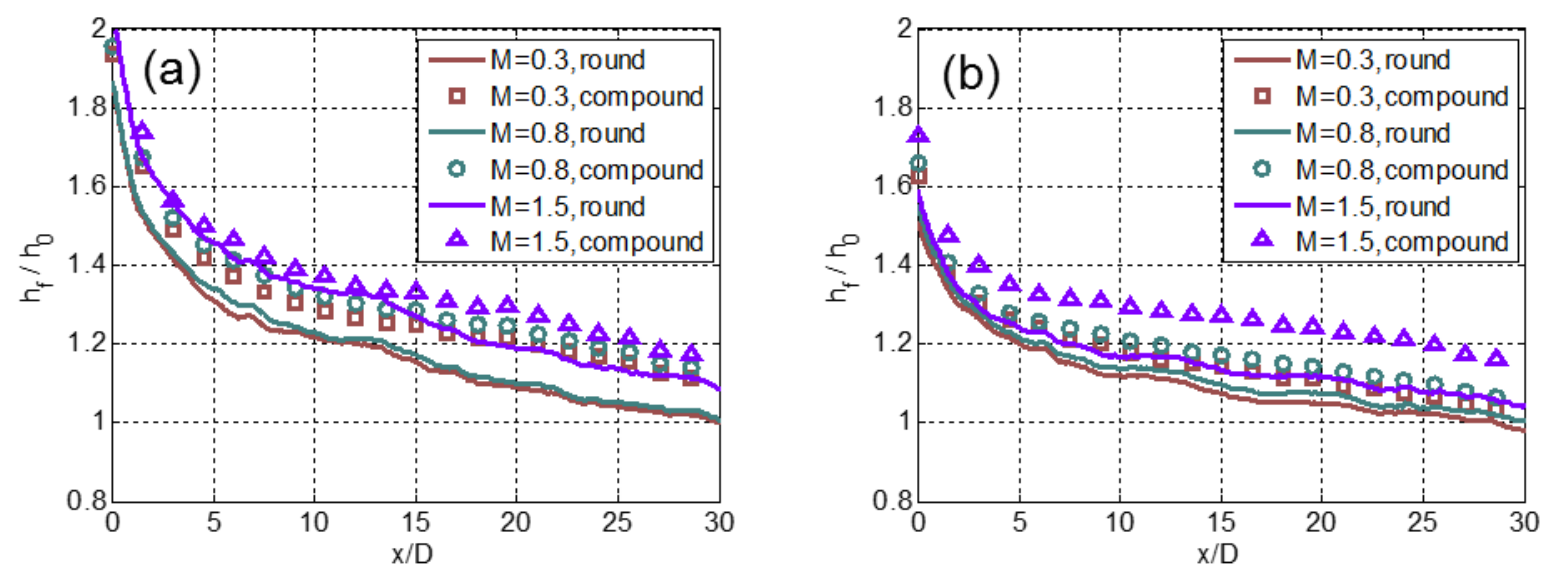

Fig. 11 Spanwise averaged heat transfer coefficient $h_{f} / h_{0}$ distribution for simple angle hole and compound angle hole with (a) $L / D=0.5$ and (b) $L / D=5.0$ with varied blowing ratio.

\subsubsection{Effect of length-to-hole diameter ratio}

The effect of length-to-diameter ratio on film cooling heat transfer coefficient has been scarcely investigated by previous studies. The main reason is that previous turbine adopts airfoil with thick outer metal sheet to meet the structure strength requirement. However, some recent new turbine designs intend to use thinner outer metal sheet for enhancing cooling efficiency and thicker inner metal sheet for improving structure strength. In such conditions, the thin outer metal sheet requires film cooling holes with short hole length-to-diameter ratios, while the shaped holes are tough to be manufactured.

The length-to-diameter ratio mainly affects the jet flow conditions at hole exit and the jet-crossflow interaction. Short-L/D holes have high jet core turbulence intensity and usually have high heat transfer coefficients. Figure 12 shows the heat transfer coefficient $h_{f} / h_{0}$ distribution for simple angle and compound angle holes at $M=1.0$ with varied length-to-diameter ratio. Generally, the heat transfer coefficient decreases gradually with the increase of $\mathrm{L} / \mathrm{D}$, regardless of compound angle. In Fig. 12a, the heat transfer coefficient patterns change little as the L/D increases. A slight increase of $h_{f} / h_{0}$ can also be observed when $\mathrm{L} / \mathrm{D}$ increases from 3.5 to 5.0. This is suspected to be the result of counteraction between decreasing jet core turbulence intensity and increasing CRVP vorticity. In Fig. 12b, the heat transfer coefficient patterns are varied with increasing lengthto-diameter ratios. When the $\mathrm{L} / \mathrm{D}$ ratio is 0.5 and 1 , the $\mathrm{h}_{\mathrm{f}} / \mathrm{h}_{0}$ patterns are quite similar to the simple angle hole. When $\mathrm{L} / \mathrm{D}$ increases to 3.5, the finger-like pattern appears because the SAMV vorticity becomes more significant and the entrainment / boundary layer pile-up are intensified. This is also suspected to be the result of counteraction between decreasing jet core turbulence intensity and increasing SAMV vorticity. 
(a)
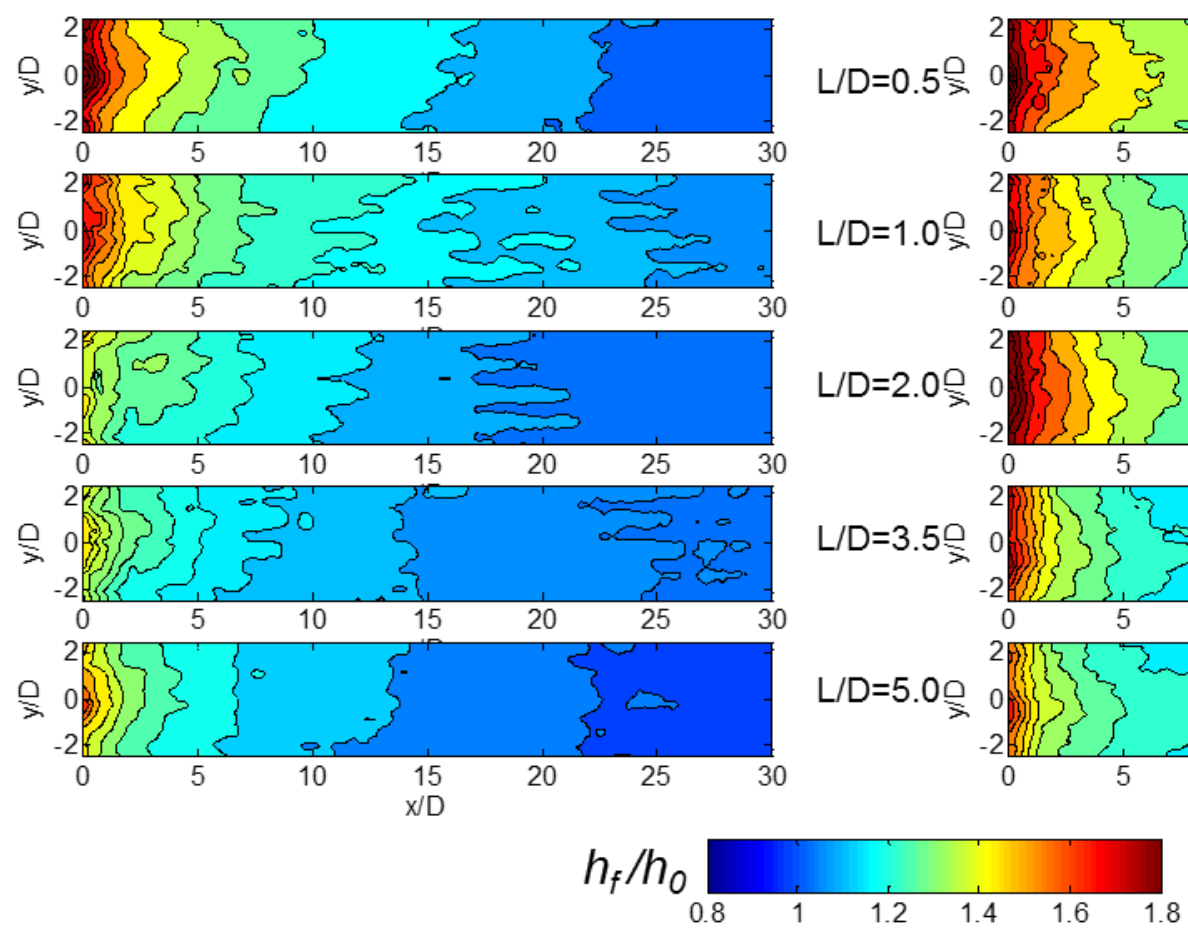

Fig. 12 Heat transfer coefficient $h_{f} / h_{0}$ distribution for (a) simple angle hole and (b) compound angle hole at $M=1.0$ with varied length-to-diameter ratio.

Figure 13 shows the spanwise averaged heat transfer coefficient $h_{f} / h_{0}$ distribution for the simple angle and compound angle holes at $\mathrm{M}=1.0$ with varied length-to-diameter ratio. The heat transfer coefficient of $\mathrm{L} / \mathrm{D}=0.5$ and 1 are the highest regardless of compound angle. In Fig. 13a, the heat transfer coefficient gradually decreases when the L/D increases from 0.5 to 3.5 , while it increases when $\mathrm{L} / \mathrm{D}$ increases from 3.5 to 5 . This leads to a minimum value of $h_{f} / h_{0}$ at $L / D=3.5$ for simple angle hole. As mentioned above, it is suspected to be the result of counteraction between decreasing jet core turbulence intensity and increasing CRVP vorticity. Increasing L/D ratio causes more fully developed in-hole jet and decays jet hole-exit turbulence intensity, resulting in decreased heat transfer level. However, increasing L/D ratio also brings about intensified CRVP, stronger fluid shearing motions, and nearwall turbulence mixing, resulting in increased heat transfer coefficient. This counteraction finally leads to a heat transfer turning point at $\mathrm{L} / \mathrm{D}=3.5$. In Fig. $13 \mathrm{~b}$, the heat transfer coefficient also decreases as blowing ratio increases and reaches a minimum value at $\mathrm{L} / \mathrm{D}=3.5$. Similar to the simple angle hole, it is suspected to be the result of counteraction between decreasing jet core turbulence intensity and increasing SAMV vorticity. Increasing L/D ratio also brings about more dominant SAMV vorticity and intensifies the hot-gas entrainment effect and the boundary layer pile-up, resulting in higher heat transfer coefficient. This counteraction also leads to a heat transfer minimum point at $\mathrm{L} / \mathrm{D}=3.5$. 

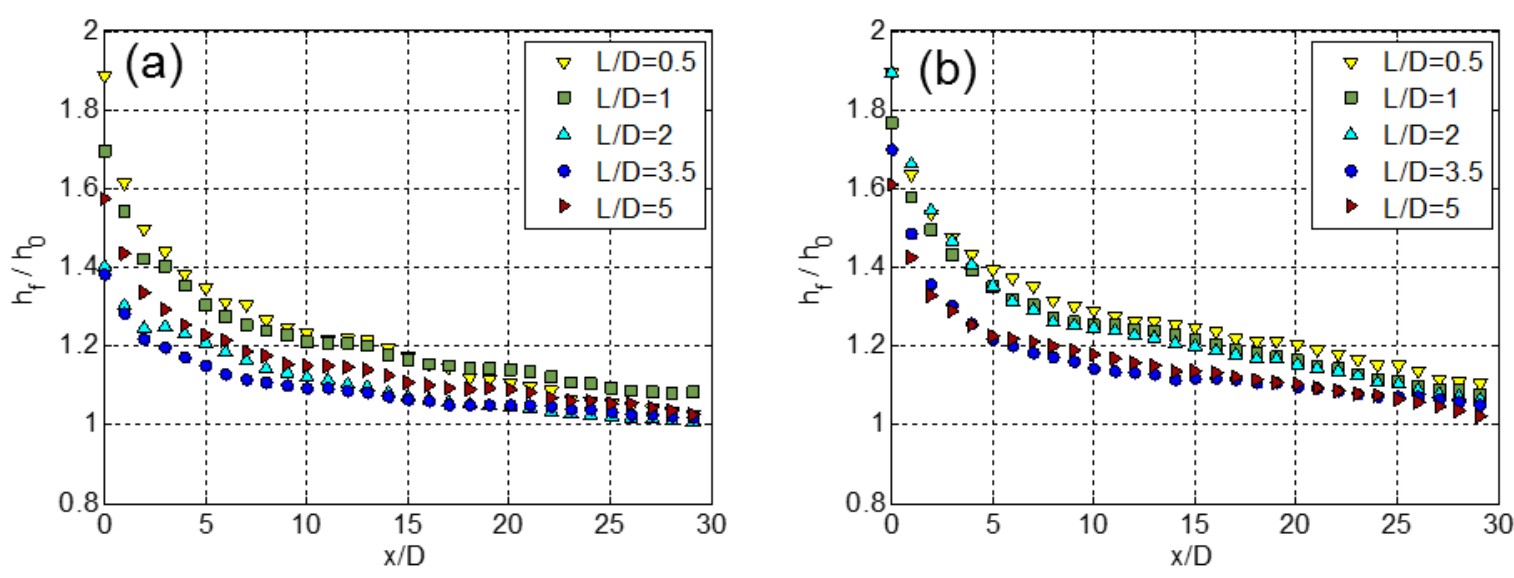

Fig. 13 Spanwise averaged heat transfer coefficient $h_{f} / h_{0}$ distribution for (a) simple angle hole and (b) compound angle hole at $\mathrm{M}=1.0$ with varied length-to-diameter ratio.

\subsubsection{Overall estimation of blowing ratio, compound angle, and length-to-hole diameter ratio}

It is indicated above that the heat transfer coefficient $h_{f} / h_{0}$ is associated with blowing ratio, compound angle, and lengthto-hole diameter ratio. Hence, an overall estimation is necessary to determine the relationship of parameters influencing the heat transfer coefficient. Figure 14 shows the area averaged heat transfer coefficient $h_{f} / h_{0}$ for simple angle and compound angle holes. Figure 14a shows that the average heat transfer coefficient of the simple angle hole increases as the blowing ratio increases. When the blowing ratio is constant, the heat transfer coefficient decreases with the increase of $\mathrm{L} / \mathrm{D}$, and the minimum value is obtained at $L / D=3.5$. Note that the region with the maximum $h_{f} / h_{0}$ is at $L / D=0.5-1.0$ and $1.6 \leq M \leq 2$, while with the minimum $h_{f} / h_{0}$ is at $L / D=2-5$ and $M \leq 0.6$. Figure $14 b$ shows the average heat transfer coefficient $h_{f} / h_{0}$ for the compound angle hole. Similar to the simple angle hole, the heat transfer coefficient of compound angle hole generally increases with the blowing ratio, and decreases with the increase of the $\mathrm{L} / \mathrm{D}$ ratio. The heat transfer coefficient of compound angle is overall higher than the simple angle hole, except for the highest heat transfer region, i.e. $\mathrm{L} / \mathrm{D}=0.5-1.0$ and $1.6 \leq \mathrm{M} \leq 2$. Note that there are two maximum $h_{f} / h_{0}$ regions, i.e. $L / D=0.5,1-2.5$ and $1.6 \leq M \leq 2$. And the lowest $h_{f} / h_{0}$ region is $L / D=3.5-5$ and $\mathrm{M} \leq 0.6$.
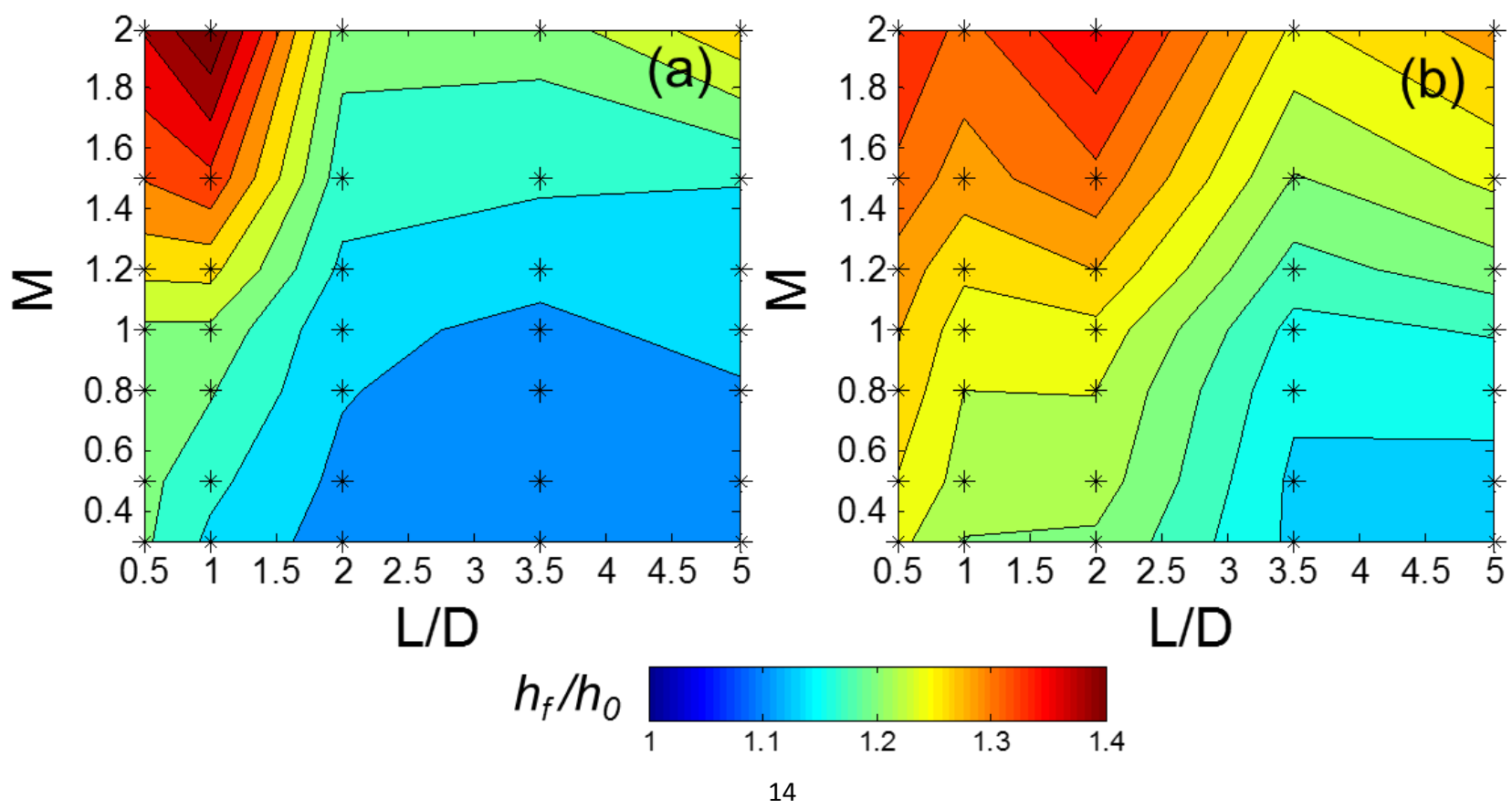


\section{Fig. 14 Area averaged heat transfer coefficient $h_{f} / h_{0}$ for (a) simple angle hole, (b) compound angle hole.}

Figure 15 shows area averaged heat transfer coefficient $h_{f} / h_{0}$ difference $\Delta\left(h_{f} / h_{0}\right)$ of compound angle hole and simple angle hole $\Delta=\beta\left(45^{\circ}\right)-\beta\left(0^{\circ}\right)$. It can be seen that the compound angle hole has $5 \sim 15 \%$ higher heat transfer coefficients at most blowing ratios and $\mathrm{L} / \mathrm{D}$ ratios compared with simple angle hole, which is consistent with the experimental data by Aga et al [20]. The higher heat transfer coefficient of compound angle hole is caused by strong lateral motion of the single axisymmetric vortex, thinner boundary layer by vortex entrainment, and higher near-wall turbulence intensity. Note that the heat transfer coefficient of compound angle hole is $5 \sim 10 \%$ lower than that simple angle hole in the region of $\mathrm{L} / \mathrm{D}=0.5-1.5$ and $1.4 \leq \mathrm{M} \leq 2$. The reason might be that the SAMV is not fully developed due to small L/D ratios, and its contribution to the jet-crossflow mixing is less significant than the CRVP of the simple angle hole. Hence the near-wall turbulence intensity is stronger for simple angle hole in this region.

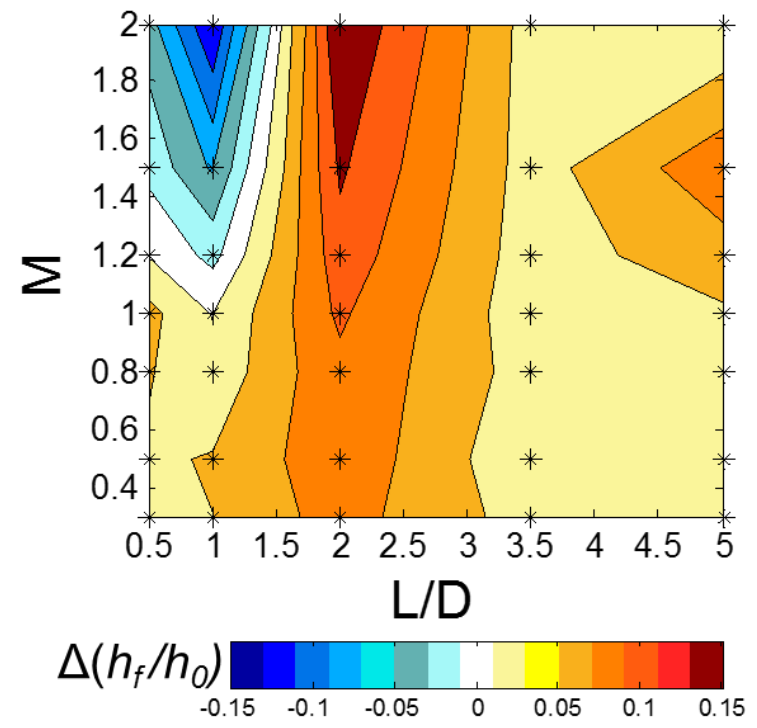

Fig. 15 Area averaged heat transfer coefficient $h_{f} / h_{0}$ difference $\Delta\left(h_{f} / h_{0}\right)$ due to compound angle: $\Delta=\beta\left(45^{\circ}\right)$ $\beta\left(0^{\circ}\right)$

\subsection{Comparison of net heat flux reduction (NHFR) method with Delta Phi $(\Delta \varphi)$ Method}

Film cooling protects the metal surface by insulating metal surface with hot gas and decreasing adiabatic temperature $T_{\text {aw }}$. However, the film also enhances the near-wall turbulence intensity and increases the surface heat transfer coefficient. Hence, it is possible to yield an undesirable increased heat load $q$ compared to cases without film cooling $q_{0}$. Thus net heat flux reduction (NHFR) method is used to evaluate the overall film cooling efficiency:

$$
\mathrm{NHFR}=1-\frac{q}{q_{0}}=1-\frac{h}{h_{0}}\left(1-\frac{\eta}{\varphi}\right)
$$

Where $\eta$ is the film cooling effectiveness, $\varphi$ is the dimensionaless temperature given by $\varphi=\left(T_{\mathrm{g}}-\mathrm{T}_{\mathrm{w}}\right) /\left(\mathrm{T}_{\mathrm{g}}-\mathrm{T}_{\mathrm{c}}\right)$, and $\mathrm{T}_{\mathrm{g}}$ is the hot gas temperature. Typically, the values of $\varphi$ in real engine range from 0.5 to 0.7 . Therefore, by assuming a constant $\varphi=0.6$, a high value of the NHFR indicates a reduction in heat load to the internal cooling system. However, Rutledge et al. [33] pointed out that the main purpose of turbine cooling is to maintain a low metal temperature, and the concept of NHFR method cannot directly provide temperature indication. So they conducted an analysis of the balance between the convective heat flux and the conduction. They provided a new Delta Phi $(\Delta \varphi)$ method that directly indicates the temperature reduction due to film cooling, which is expressed as: 


$$
\Delta \phi=\phi-\phi_{0}=\frac{T_{g}-T_{w}}{T_{g}-T_{c}}-\frac{T_{g}-T_{w 0}}{T_{g}-T_{c}}=\frac{T_{w 0}-T_{w}}{T_{g}-T_{c}}
$$

Here evidently the $\Delta \varphi$ indicates a temperature reduction from $\mathrm{T}_{\mathrm{w} 0}$ to $\mathrm{T}_{\mathrm{w}}$ often caused by improving heat transfer efficiency or increasing coolant mass flow. The measurements of adiabatic film effectiveness [23] and heat transfer coefficient offer opportunities to make a comprehensive investigation of the cooling efficiency in this paper. So the NHFR method and $\Delta \varphi$ method are compared and evaluated based on the experimental data of film hole with varied compound angle and length-todiameter ratio.

Figure 16 shows the distribution of the $\Delta \varphi$ contour and the NHFR contours of simple angle hole with $\mathrm{L} / \mathrm{D}=5$ and $\mathrm{M}=0.5$. Figure 16a shows the $\Delta \varphi$ contour, while 16b and 16c show the NHFR contours. Figure 16a shows that film cooling can effectively reduce the wall temperature in most regions, and the maximum dimensionless temperature can be reduced by 0.4 . In the regions on both sides of the hole, i.e. $\mathrm{x} / \mathrm{D} \leq 10, \mathrm{y} / \mathrm{D} \leq-1$ or $\mathrm{y} / \mathrm{D} \geq 1, \Delta \varphi$ is close to 0 indicating that wall is not effectively cooled since there is no cooling air coverage. Figures $16 \mathrm{~b}$ and $16 \mathrm{c}$ show the change of NHFR contours with different values of $\varphi$. The NHFR is positive in the regions covered by the coolant jet. On the contrary, the NHFR is negative in the regions where the wall is not covered by the film on both sides of the hole, indicating that the heat flux transferred from the high temperature gas to the wall surface is increased compared to that without film cooling. This is caused by two reasons: 1) lack of film cooling that leads to high adiabatic wall temperature, and 2) flow acceleration in regions between film holes due to film jet blockage effect that leads to high heat transfer coefficients. Both the two reasons result in increased heat flux from high temperature gas to the wall surface.

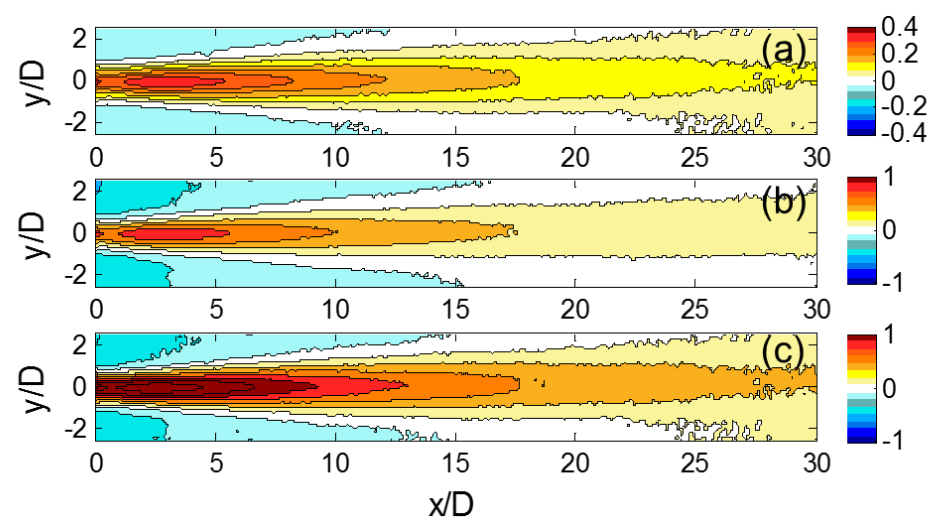

Fig. 16 Simple angle hole contours with $L / D=5$ and $M=0.5$, (a) $\Delta \varphi$ contours, (b) NHFR contours, $\varphi=0.6$, (c) NHFR contours, $\varphi=0.4$

Figure 17 shows spanwise averaged NHFR distribution for simple angle and compound angle hole at $\mathrm{L} / \mathrm{D}=5$. With the increase of the blowing ratios, the NHFR decreases gradually, since the film cooling effectiveness decreases and heat transfer coefficient increases simultaneously. Note that the NHFR is mostly negative when the blowing ratio is over 1.2. Figure 17a shows that the NHFR is mostly negative at regions 5-10D downstream of the hole due to the jet blow-off and enhanced turbulence intensity. However, in the compound angle hole shown in Fig. 17b, the jet blow-off phenomenon is weakened and the NHFR downstream the hole is comparably large. Although the overall film cooling effectiveness of compound angle hole is greater than simple angle hole, its heat transfer coefficient is also greater than simple angle hole. Hence, there is no obvious difference in NHFR distribution between the simple angle hole and compound angle hole in regions 5D downstream the hole. 

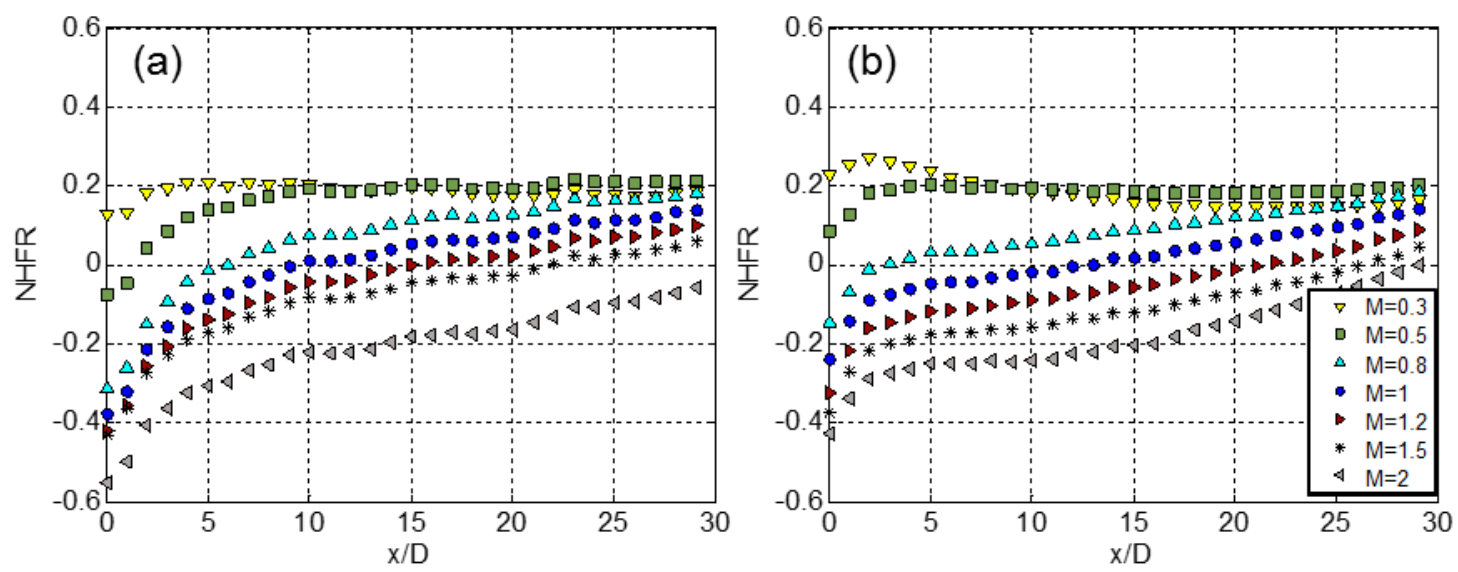

Fig. 17 Spanwise averaged NHFR distribution for (a) simple angle hole and (b) compound angle hole at L/D=5.

Figure 18 shows spanwise averaged $\Delta \varphi$ distribution for simple angle and compound angle hole at $\mathrm{L} / \mathrm{D}=5$. Similar to the distribution of NHFR, the $\Delta \varphi$ decreases gradually with the increase of the blowing ratio. When the blowing ratio is over 1.5, the $\Delta \varphi$ is negative in certain regions $\mathrm{x} / \mathrm{D}<5$, which is caused by low film coverage. A large difference of $\Delta \varphi$ distribution is noticed between simple angle and compound angle holes, which is not observed in the NHFR method. The $\Delta \varphi$ value of compound angle hole in Fig. 18b is higher than that of the simple angle hole in Fig. 18a, which demonstrate that compound angle hole provides a better isolation of the high temperature gas and metal walls than the simple angle hole.
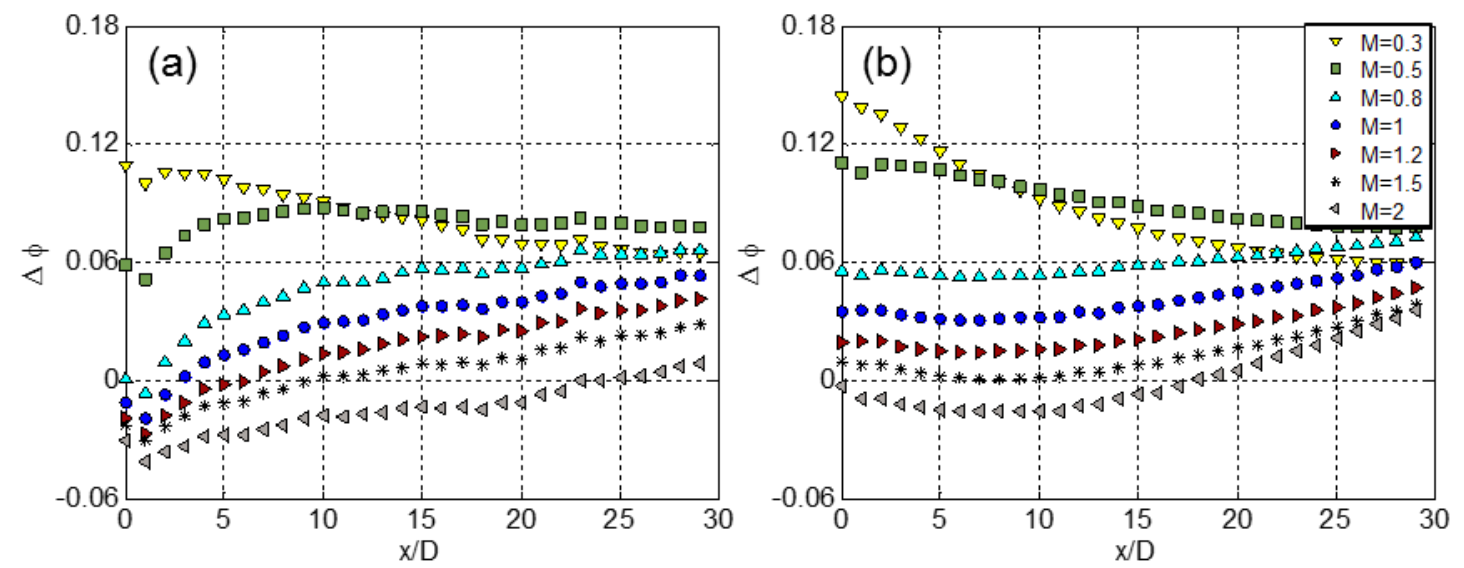

Fig. 18 Spanwise averaged $\Delta \varphi$ distribution for (a) simple angle hole and (b) compound angle hole at $L / D=5$.

Figure 19 shows the area averaged NHFR and $\Delta \varphi$ for compound angle hole. In Fig. 19a, NHFR is positive when $M \leq 1$, indicating that film cooling helps to reduce the heat flux transferred to the metal wall. NHFR is negative when $M \geq 1$, indicating that the film cooling plays a negative role. This is caused by decreased film effectiveness and increased heat transfer coefficient. However, it is not quite proper to evaluate the film cooling performance because little information of temperature can be obtained. As can be seen from Fig. 19b, $\Delta \varphi$ is positive when $\mathrm{M} \leq 1.6$, indicating that the temperature of the metal wall surface is reduced in this range of blowing ratio. When $\mathrm{L} / \mathrm{D}=0.5-3$ and $\mathrm{M} \geq 1.6, \Delta \varphi$ is negative, indicating that there is no benefit using film cooling. Therefore, if the film cooling performance is judged from the viewpoint of NHFR, film cooling is beneficial only if the blowing ratio is low $(\mathrm{M} \leq 1)$, and this method still cannot help judge the influence on the wall temperature. If $\Delta \varphi$ method is used, film cooling is still beneficial and reduces wall temperature at higher blowing ratios $(\mathrm{M} \leq 1.6)$. 

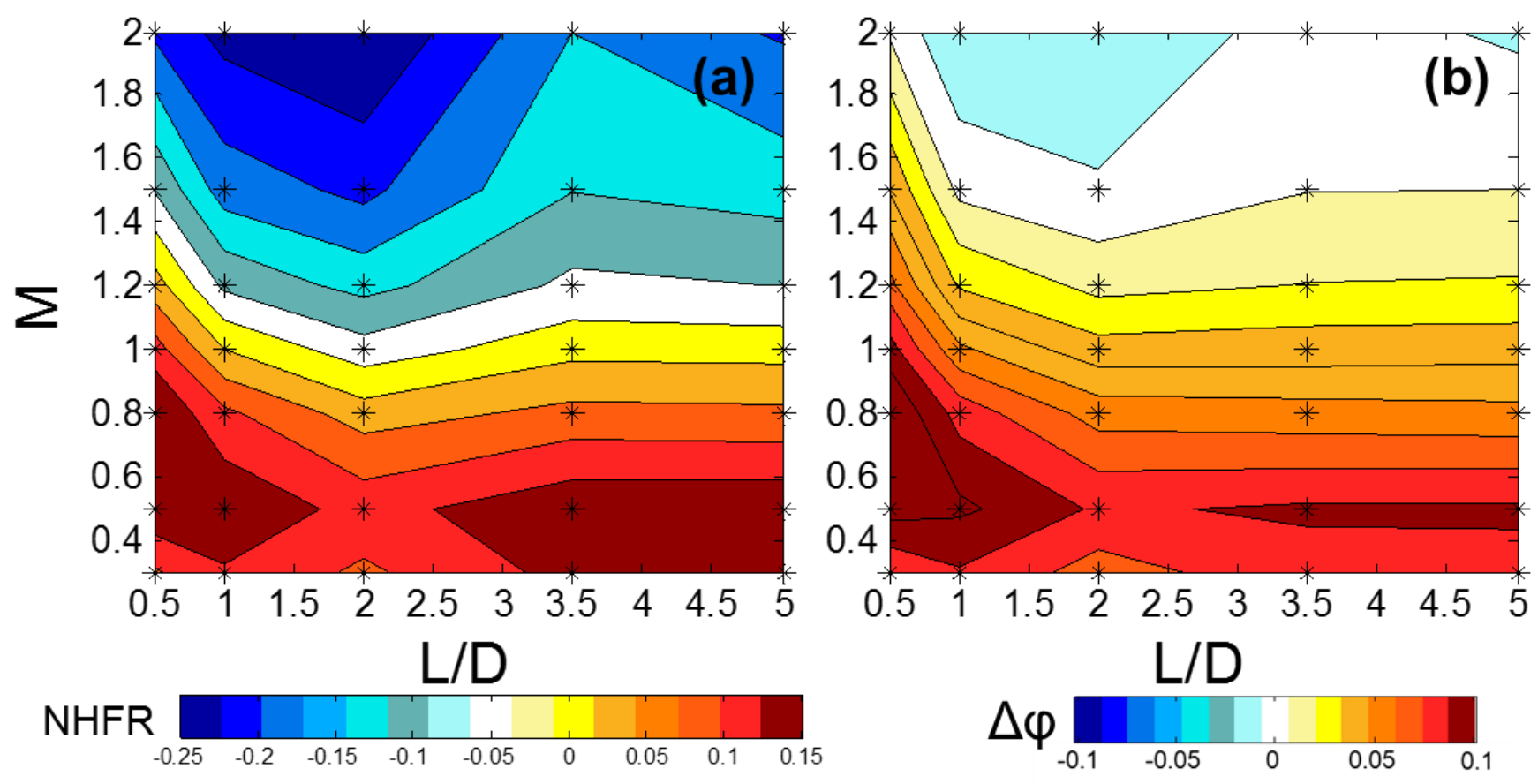

Fig. 19 Area averaged (a) NHFR and (b) $\Delta \varphi$ for compound angle hole

\section{Conclusions}

The present study investigates the heat transfer coefficient on a flat plate surface downstream a row of simple angle and compound angle holes using steady liquid crystal (SLC) technique. Effect of blowing ratio, compound angle, and length-todiameter ratio are indicated by detailed local, spanwise averaged, and area averaged heat transfer coefficient data. The overall film cooling performance is also evaluated using NHFR method and $\Delta \varphi$ method by combining film effectiveness and heat transfer coefficient data. Based on the large matrix of measurements data, new heat transfer coefficient correlations are developed for simple angle and compound angle holes, respectively. The main conclusions are listed as follows:

(1) Increasing blowing ratio brings the increase of heat transfer coefficient $h_{f} / h_{0}$, regardless of compound angle. Increasing blowing ratio leads to increased momentum jet and stronger jet-crossflow interaction, which enhances the turbulence intensity of near-wall fluid and reduces the boundary layer thickness. The effect of compound angle is limited when L/D is small, while is significant when $\mathrm{L} / \mathrm{D}$ is large. Compound angle enhances the heat transfer coefficient because the single asymmetric vortex entrains boundary layer fluid to the other side and thinner the boundary layer.

(2) The length-to-diameter ratio mainly affect the jet-crossflow interaction and short L/D enhances near-wall turbulence intensity, which leads to high heat transfer coefficient. The heat transfer coefficient gradually decreases when the $\mathrm{L} / \mathrm{D}$ increases from 0.5 to 3.5 , while it increases when $\mathrm{L} / \mathrm{D}$ increases from 3.5 to 5 . This leads to a minimum value of $\mathrm{h}_{\mathrm{f}} / \mathrm{h}_{\mathrm{o}}$ at $\mathrm{L} / \mathrm{D}=3.5$ for both simple angle and compound angle holes. This is suspected to be the result of counteraction between decreasing jet core turbulence intensity and increasing CRVP or SAMV vorticity.

(3) The overall film cooling performance is also evaluated using NHFR method and $\Delta \varphi$ method. The NHFR method provides a lower blowing ratio value, below which the film cooling has a positive gain and reduces the heat flux transferred to the wall. However, the $\Delta \varphi$ method provides a higher blowing ratio, below which it is beneficial and reduces metal wall temperature. Meanwhile, the $\Delta \varphi$ method can help judge the effectiveness of different film cooling techniques by evaluating temperature reduction, which is more convenient for film cooling design. 


\section{Acknowledgement}

The authors would like to acknowledge the financial supports from National Natural Science Foundation of China (No. 51676106 and No. U1613204).

\section{Nomenclature}

Latin

$$
\begin{aligned}
\mathrm{D} & =\text { film hole diameter }(\mathrm{m}) \\
\mathrm{DR} & =\text { density ratio } \\
\mathrm{H} & =\text { boundary layer shape factor } \\
\mathrm{h} & =\text { heat transfer coefficient }\left(\mathrm{W} / \mathrm{m}^{2} \mathrm{~K}\right) \\
\mathrm{I} & =\text { momentum flux ratio } \\
k & =\text { thermal conductivity }(\mathrm{W} / \mathrm{mK}) \\
\mathrm{L} & =\text { film hole length }(\mathrm{m}) \\
\mathrm{M} & =\text { blowing ratio } \\
\mathrm{P} & =\text { spanwise hole pitch }(\mathrm{m}) \\
q & =\text { heat flux }(\mathrm{W}) \\
\mathrm{T} & =\text { temperature }(\mathrm{K}) \\
t & =\text { wall thickness }(\mathrm{m}) \\
\mathrm{Tu} & =\text { turbulence intensity } \\
\mathrm{U} & =\text { mean velocity components } \\
\mathrm{u} & =\text { fluctuating velocity components } \\
\mathrm{X} & =\text { streamwise coordinate }(\mathrm{m}) \\
\mathrm{Y} & =\text { spanwise coordinate }(\mathrm{m}) \\
\mathrm{Z} & =\text { wall-normal coordinate }(\mathrm{m}) \\
\eta & =\text { film cooling effectiveness } \\
\varphi & =\text { dimensionless temperature } \\
\omega & =\text { vorticity } \\
\delta & =\text { boundary layer thickness }(\mathrm{m}) \\
\delta^{*} & =\text { boundary layer displacement thickness }(\mathrm{m}) \\
\kappa & =\text { boundary layer momentum thickness }(\mathrm{m})
\end{aligned}
$$

Subscripts

$$
\begin{aligned}
& \mathrm{c}=\text { coolant } \\
& \mathrm{f}=\text { flow with film cooling } \\
& \mathrm{j}=\text { jet } \\
& \mathrm{m}=\text { mainstream } \\
& \mathrm{n}=\text { axis direction } \\
& 0=\text { flow without film cooling }
\end{aligned}
$$

\section{Reference}

[1] Liang, G., 2009, "Turbine airfoil with multiple near wall compartment cooling." U.S. Patent 7,556,476 B1. 
[2] Li, W., Li, X., Ren, J., Jiang, H., Yang, L., and Ligrani, P., 2017, "Effect of Reynolds Number, Hole Patterns and Hole Inclination on Cooling Performance of an Impinging Jet Array: Part I-Convective Heat Transfer Results and Optimization,” ASME J. Turbomach., 139(4), p. 041002.

[3] Yang, L., Parbat, S. N., Min, Z., and Chyu, M. K., 2017, "Effect of topology on hybrid-linked jet impingement," Int. J. Heat Mass Transfer, 108, 671-679.

[4] Li, W., Xu, M., Ren, J. and Jiang, H., 2017, “Experimental Investigation of Local and Average Heat Transfer Coefficients Under an Inline Impinging Jet Array, Including Jets With Low Impingement Distance and Inclined Angle," ASME J Heat Transfer, 139(1), p.012201.

[5] Hale, C. A., Plesniak, M. W., and Ramadhyani, S., 2000, "Film Cooling Effectiveness for Short Film Cooling Holes Fed by a Narrow Plenum,” ASME J. Turbomach., 122, pp. 553-557.

[6] Hay, N., Lampard, D., and Saluja, C. L., 1985, "Effects of Cooling Films on the Heat Transfer Coefficient on a Flat Plate with Zero Mainstream Pressure Gradient," ASME J. Gas Turbines Power, 107, pp. 105-110.

[7] Ammari, H. D., Hay, N., and Lampard, D., 1990, "The Effect of Density Ratio on the Heat Transfer Coefficient from a Film-Cooled Flat Plate," ASME J. Turbomach., 112 (3), pp. 444-451.

[8] Burd, S. W., and Simon, T. W., 1999, "Turbulence Spectra and Length Scales Measured in Film Coolant Flows Emerging From Discrete Holes,” ASME J. Turbomach., 121, pp. 551-557.

[9] Burd, S. W., Kaszeta, R. W., and Simon, T. W., 1998, "Measurements in Film Cooling Flows: Hole L/D and Turbulence Intensity Effects,” ASME J. Turbomach., 120, pp. 791-798.

[10] Baldauf, S., Schulz, A., and Wittig, S., 2001, "High Resolution Measurements of Heat Transfer Coefficients From Discrete Hole Film Cooling,” ASME J. Turbomach., 123, pp. 749-757.

[11] Lutum, E., and Johnson, B. V., 1999, "Influence of the Hole Length-toDiameter Ratio on Film Cooling With Cylindrical Holes,” ASME J. Turbomach., 121, pp. 209-216.

[12] Sen, B., Schmidt, D. L., and Bogard, D. G., 1996, "Film Cooling With Compound Angle Holes: Heat Transfer," ASME J. Turbomach., 118(4), pp. 800-806.

[13] Ekkad, S. V., Zapata, D., and Han, J. C., 1997, "Film Effectiveness Over a Flat Surface with Air and CO2 Injection Through Compound Angle Holes Using a Transient Liquid Crystal Image Method,” ASME J. Turbomach., 119 (3), pp.587-593.

[14] Ekkad, S., Zapata, D., and Han, J., 1997, "Heat Transfer Coefficients Over a Flat Surface With Air and CO2 Injection Through Compound Angle HolesUsing a Transient Liquid Crystal Image Method,” ASME J. Turbomach., 119(3), pp. 580-586.

[15] Goldstein, R. J., and Jin, P., 2001, “Film Cooling Downstream of a Row of Discrete Holes With Compound Angle," ASME J. Turbomach., 123 , pp. 222-230.

[16] Nasir, H., Ekkad, S. V., and Acharya, S., 2001, "Effect of Compound Angle Injection on Flat Surface Film Cooling With Large Streamwise Injection Angle,” Exp. Therm. Fluid Sci., 25 , pp. 23-29。

[17] Ligrani, P. M., Wigle, J. M., Ciriello, S., and Jackson, S. W., 1994 "Film-Cooling From Holes With Compound Angle Orientations: Part 1-Results Downstream of Two Staggered Rows of Holes With 3d Spanwise Spacing," ASME J. Heat Transfer, 116 (2), pp. 341-352.

[18] Ligrani, P. M., Wigle, J. M., and Jackson, S. W., 1994 "Film-Cooling From Holes With Compound Angle Orientations: Part 2-Results Downstream of a Single Row of Holes With 6d Spanwise Spacing," ASME J. Heat Transfer, 116 (2), pp. 353-362.

[19] Boyd, E. , McClintic, J. , Chavez, K. , and Bogard, D. , 2014, “ Direct Measurement of Heat Transfer Coefficient Augmentation at Multiple Density Ratios,” ASME Paper No. GT2014-27085.

[20] Schreivogel P., Pfitzner M., 2015. "Heat Transfer Measurements Downstream of Trenched Film Cooling Holes Using a Novel Optical Two-Layer Measurement Technique”, ASME Paper GT2015-42385. 
[21] Aga, V., Rose, M., and Abhari, R. S., 2008, "Experimental Flow Structure Investigation of Compound Angled Film Cooling,” ASME J. Turbomach., 130, p. 031005.

[22] Aga, V., and Abhari, R. S. , 2011, "Influence of Flow Structure on Compound Angled Film Cooling Effectiveness and Heat Transfer," ASME J. Turbomach., 133(3), p. 031029.

[23] W. Li, X. Li, J. Ren, H. Jiang ,2017, "High Resolution Measurements of Film Cooling Performance of Simple and Compound Angle Cylindrical Holes with Varying Hole Length-to-Diameter Ratio-Part I: Adiabatic Film Effectiveness," International Journal of Thermal Science, 124, pp. 146-161.

[24] Li, X., Ren, J. and Jiang, H., 2016, “Influence of different film cooling arrangements on endwall cooling,” Int. J. Heat Mass Transfer, 102, pp.348-359.

[25] Li, X., Ren, J., and Jiang, H., 2015, "Film cooling effectiveness distribution of cylindrical hole injections at different locations on a vane endwall," Int. J. Heat Mass Transfer, 90, 1-14.

[26] Li, X., Ren, J., and Jiang, H. 2016, "Multi-row film cooling characteristics on a vane endwall," Int. J. Heat Mass Transfer, 92, 23-33.

[27] Y. Rao, S. S. Zang, 2010, "Calibrations and the measurement uncertainty of wide-band liquid crystal thermography," Measurement Science \& Technology, 21, p. 015105.

[28] Li, W., Yang, L., Ren, J., Jiang, H., 2016, "Effect of thermal boundary conditions and thermal conductivity on conjugate heat transfer performance in pin fin arrays,” Int. J. Heat Mass Transfer, 95, 579-592.

[29] N. Abdullah, A.R.A. Talib, H.R.M. Saiah, A.A. Jaafar, M.A.M. Salleh, 2009, "Film thickness effects on calibrations of a narrowband thermochromic liquid crystal," Experimental Thermal and Fluid Science, 33, pp.561-578.

[30] Moffat, R. J., 1985, “Using Uncertainty Analysis in the Planning of an Experiment,” ASME J. Fluids Eng., 107, pp. $173-178$.

[31] Yuen, C.H.N., Martinez-Botas, R.F., 2005, "Film Cooling Characteristics of Rows of Round Holes at Various Streamwise Angles in a Crossflow: Part II. Heat Transfer Coefficients,” Int. J. Heat Mass Transfer, 48, pp. $5017-$ 5035.

[32] Baldauf, S., Scheurlen, M., Schulz, A., and Wittig, S., 2002, "Heat Flux Reduction from Film Cooling and Correlation of Heat Transfer Coefficients from Thermographic Measurements at Engine Like Conditions," ASME J. Turbomach., 124 (4), pp. 699-710.

[33] Rutledge, J. L., Polanka, M. D., and Bogard, D. G., 2016, "The Delta Phi Method of Evaluating Overall Film Cooling Performance,” ASME J. Turbomach., 138(7), 071006. 